التربية الوقائية وعلاقتها بالتمكين النفسي

التربية الوقائية وعلاقتها بالتمكين النفسي لاى عينة من طلبة المرحلة الثانوية بمكة الثكن

\title{
المكرمة (1)
}

إعداد

سهير محمد التوني

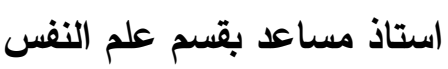

علياء أحمد الحازمي طالبة ماجستير

كلية الاداب - جامعة الملك عبد العزيز

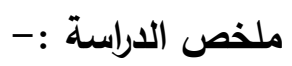

هدفت الدراسة الحالية إلى التعرف على العلاقة بين التربية الوقائية والتمكين النفسي لاى

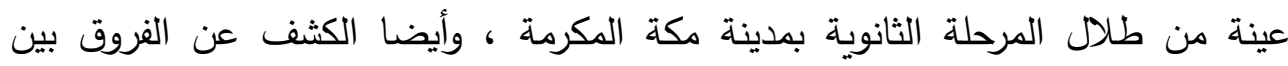

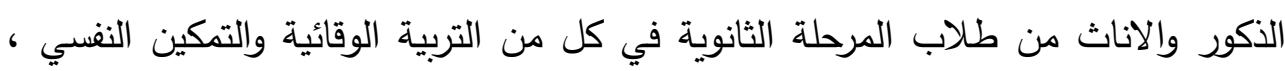

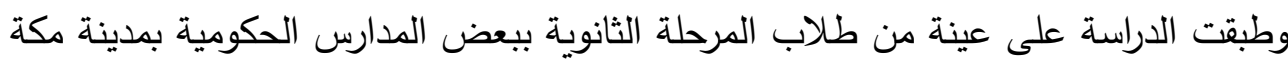

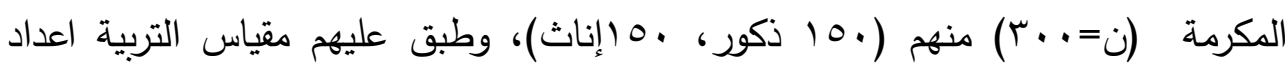

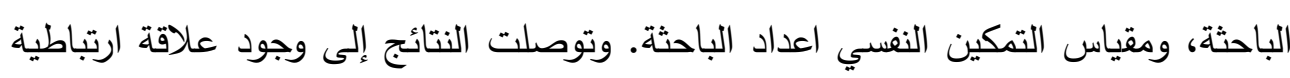

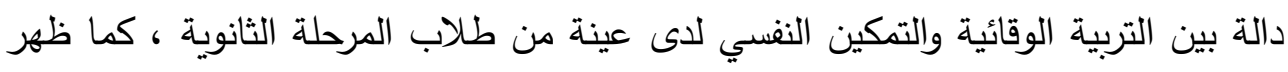

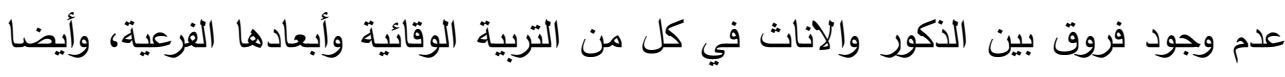
عدم وجود فروق بين الذكور والاناث في التمكين النفسي وأبعاده الفرعية.

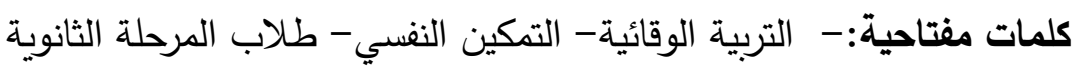

استمدت مادة الدراسة من رسالة ماجستير خاصة بالباحثة الأولى، تحت إثراف د/ سهير

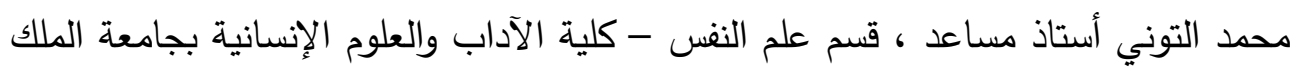
عبد العزيز 
أ/ علياء أحمد الحازمي د/ سهير محمد التوني

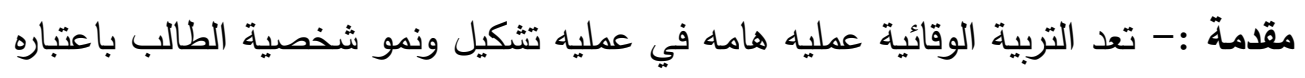
جزء مهم واساسي في العملية التربوية والتعليمية واللبنة الأساسية التي يقوم عليها تقدم ورقي

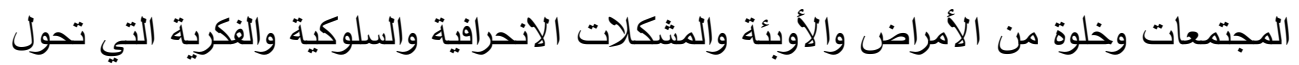

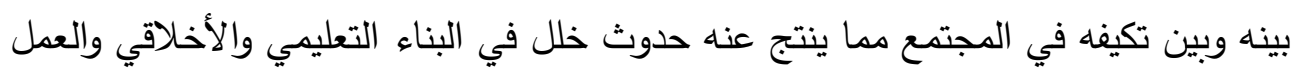
على تربيتهم تربية صالحة خالية من المشكلات. (سليم ، 1991 :

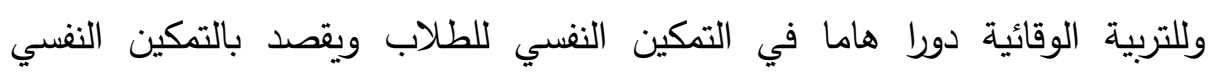
Psychological empowerment قدرات واستعدادات نفسيه تجعله قادرا على التحكم واتخاذ القرارات المناسبة في مواقف الحياة

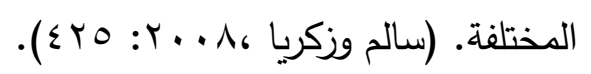
ويعتبر التمكين النفسي أيضا من المفاهيم المعاصرة التي ترتقي بالعنصر البشري في

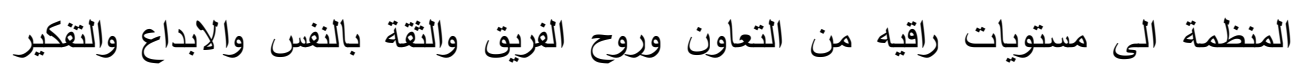

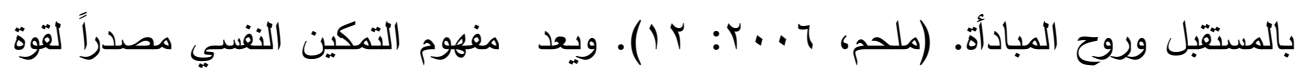
وإيجابية الذات واتخاذ القرار وتحمل المسؤولية والوصول الى الكفاءة الذاتية الذي يؤدي تتميته الى تمكين الأطفال وتقوية جوانب الثخصية لديهم، وبالتالي التصدي لمحاولات

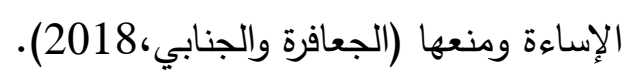
وترى الباحثة أن المعلم والمدرسة لهما دور كبير ومهم يساعد الطلاب والطالبات على تتميه وتقوية التمكين النفسي لديهم ومساعدتهم على القيام برفع مستوى الوعي والاستبصار لديهم بوقاية أنفسه من جميع المخاطر التي يعيشونها عن طريق استراتيجيات وأساليب حديثه

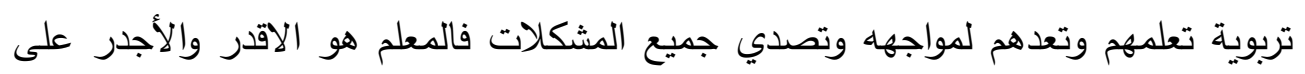
فهم الطلاب والتعرف على احتياجاتهم والعمل معهم بما يمتلك من مهارات واستراتيجيات بمساعدة المؤسسة الام المدرسة وذلك بالتواصل مع اسر الطلبة والتخطيط معهم للوصول بالطالب الى اعلى مستويات التمكين النفسي في المستقبل والقدرة على تحمل المسؤوليات واتخاذ القرارات المناسبة لهم بكل حريه , وان التربية الوقائية والتمكين النفسي لاى الطيلاب

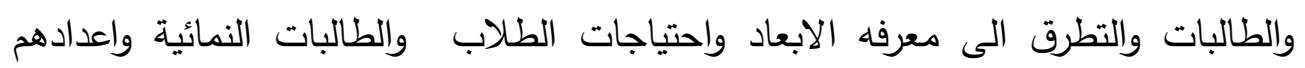
لمواجهتها وتصدى جميع المشكلات وخصوصا في مرحله المراهقة وتحديدا في مرحله 
التربية الوقائية وعلاقتها بالتمكين النفسي

الثانوية فهي مرحله عناد وتمرد ومرحله استقلال وتكوين الثخصية وبيان مدى اهميه احتياج تلك الفئه او المرحلة لتلك الدراسات التي تتناول المتغيرين التربية الوقائية والتمكين النفسي ملتي حتى لا يقعون فريسه سهله للإغواء من الأعداء او رفقاء السوء ـ ـوسنحاول في الدراسة الحالية الكثف عن علاقة كل من التربية الوقائية والتمكين النفسي لدى طلاب وطالبات المرحلة الثانوية.ة. مشكله الدراسة:

يعد التمكين النفسي مدخلا مهما وفعالا في الترقي والتطور المستمر على كافة المستويات .

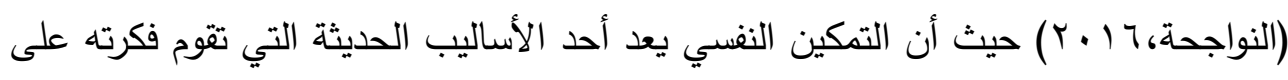
منح الأفراد الثقة وتفويضهم السلطات والاستقلالية، مما يولد لديهم شعورا بالثقة والحافز لتهي

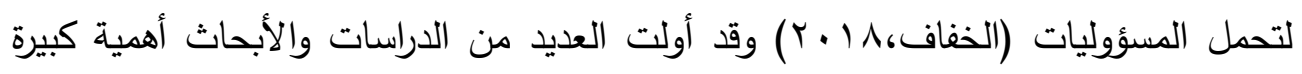
في الآونة الأخيرة لموضوع التربية الوقائية والتمكين النفسي لما له من اهميه في زيادة

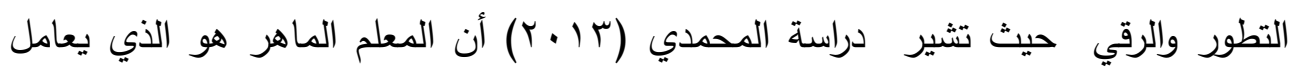
الطلاب بعدل ويكيف ممارساته وفقا لما يشاهده ويعرفه عن الطلبة من حيث اهتماماتهم

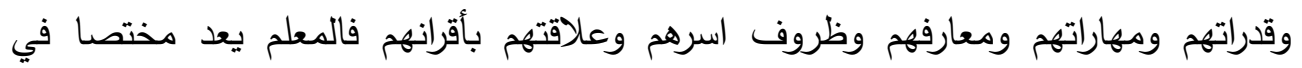
التعليم والتعلم ويملك مهارات التشخيص والعلاج من خلال تعلمه المستمر مع المشكلات التي تحصل في المجال التربوي. وأيضا دراسة ادرينا Adrina)(2013 والتي تؤكد على ان التربية الوقائية لها تأثير كبير و مهم على توعيه الأفراد اجتماعيا ونفسيا بحيث تؤثر على

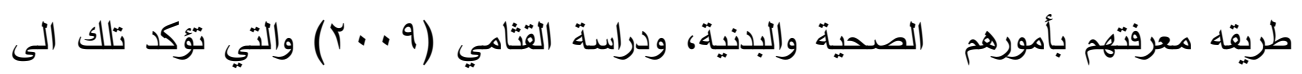

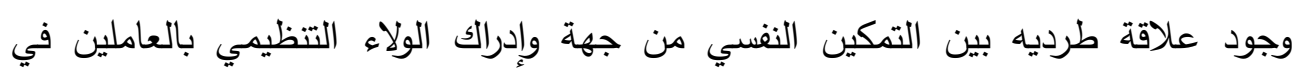
المستشفى بأهية التمكين النفسي وفوائده للمنظمة والافراد وذلك بتحقيق اليات متعددة منها التوعية والتدريب المستمر للمشرفين وإعطاء مفهوم الولاء التظيمي اهتمام أكبر بالقيادات في المجال الصحي من خلال تتميه إدراك العاملين بالولاء التظيمي. ودراسة لبرنامج وقائي

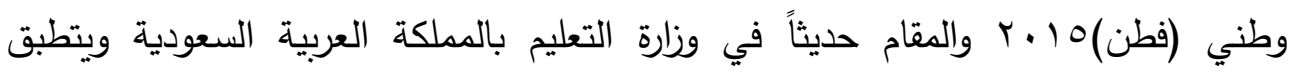
البرنامج الوقائي فطن في جميع مدارس المملكة للطلاب والطالبات والذي يعنى بتنمية 
أ/ علياء أحمد الحازمي د/ سهير محمد التوني

مهارات الطلاب والطالبات الشخصية والاجتماعية لوقاية أبنائنا وتعزيز القيم الاجتماعية والأخلاقية في إطار تعاليم الدين الإسلامي ونشر الوعي الصحي والاجتماعي والنفسي.

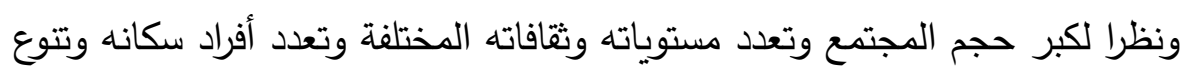

هوياته وجنسياته واختلاف أساليب التربية الوقائية قديما عن اساليب التربية الوقائية حديثا والتغيرات الكبيرة المفاجئة التي طرأت وظهرت على مجتمعاتتا في وقتتا الحالي والدخيلة علينا والتي لا تتسم بالتربية الصحيحة غالبا وقله الوعي في تعزيز الجانب أو الدور الوقائي والتحصيني والتمكين النفسي بشكل دائم ومستمر وضعف كلا من دور المدرسة والاسرة بالقيام بدورها التربوي وعدم قدرتها على مواكبه تلك التغيرات وتقليل فرصه القيام بعمل ندوات ومحاضرات توعويه تعزز الجانب الوقائي وتساعد الطلاب والطالبات على تتمية التمكين النفسي لإدارة ذواتهم بثكل سليم وصحيح. قامت الباحثة بالبحث عن تلك المشكلة موضوع الدراسة والتي تعتبر في مجتمعنا الحالي حديث الساعة نظرا لكثرة المشكلات وظهور التطرفات الفكرية والانحرافات السلوكية خصوصا في مرحله المراهقة وحاجه الطلاب والطالبات لرفع مستوى الوعي الوقائي لديهم لكي يتمكنوا نفيا من مواجهه المخاطر والمشكلات بكل كفاءة. مما سوغ للباحثة القيام بالدراسة الحالية لكثف العلاقة ما بين التربية الوقائية والتمكين النفسي لدى طلاب وطالبات المرحلة الثانوية أسئلة الدراسة :-

مما سبق فان مشكله الدراسة تشتمل على التساؤلات التالية: 1-هل توجد علاقة ارتباطية دالة بين التربية الوقائية وأبعادها الفرعية والتمكين النفسي تلئي

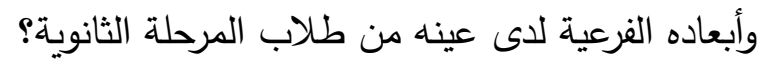
r- هل توجد فروق ذات دالة بين الذكور والاناث من طلاب المرحلة الثانوية في التربية الوقائية وأبعادها الفرعية. r- هل توجد فروق ذات دالة بين الذكور والاناث من طلاب المرحلة المرحلة الثانوية في التمكين النفسي وأبعاده الفرعية ؟ دوفي 


\section{التربية الوقائية وعلاقتها بالتمكين النفسي}

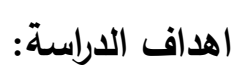

1- التعرف على العلاقة بين التربية الوقائية، والتمكين النفي ل لدى عينه من طلاب المرحلة الثانوية. r- الكثف عن الفروق بين الذكور والاناث من طلاب المرحلة الثانوية في كل من التربية الوقائية والتمكين النفسي الونائ أهميه الدراسة: أولا: الأهمية النظريـة الاهية

ا- إثراء المكتبة العربية والميدان التربوي بإطار نظري عن متغيرات حديثة نسبيا وهي التربية الوقائية والتمكين النفسي يستقيد منها المهتمين بالمجال. ץ- ندرة الدراسات التي جمعت بين كل من التربية الوقائية وعلاقتها بالتمكين النفسي لدى بالهين الطلاب والطالبات في مرحلة المراهقة وخصوصا في المرحلة الثانوية، حيث تعتبر الدراسة الحالية على حد علم الباحثة هي اول دراسة في المملكة العربية السعودية r- تساعد الدراسة المهتمين بالطلاب في المرحلة الثانوية لتهيئتهم وقائيا وتمكينهم مجتمعيا وذلك لبناء جيل سليم واعي قادر على التمكين وإدارة الذات. ؟- تتناول هذه الدراسة مرحلة عمرية مهمة جدا وهي مرحلة المراهقة والتي تتراوح اعمارهم مابين (7 (1-1) سنة وهي مرحلة حرجة تحتاج الى تلبية كافة متطلبات النمو المختلفة بما فيها من الناحية النفسية والتي تحتاج ايضا الى وعي وتفهم واهتمام من قبل التربويين للتعامل

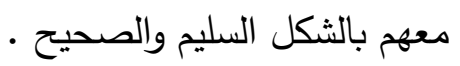

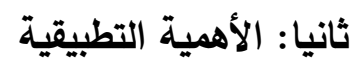

1- ما ستسفر عنه نتائج الدراسة من استفادة كل من التربويين والمدرسين والقائمين بالشأن التعليمي الحديثة لتطوير أساليب ومفاهيم التربية الوقائية وتتميه التمكين النفسي للطلاب لتبن والطالبات وذلك للقيام بعمل برامج وقائية مكثفه لهح • r- قيام الباحثة بتصميم واعداد مقياسين لكل من متغيرات الدراسة وهي مقياس التربية الوقائية ومقياس التمكين النفسي حيث انه من الممكن الاستفادة منه مستقبلا فيما بعد وهين لذوي الثأن التعليمي والتربوي. 


$$
\text { مصطاح علياء أحمد الحازمي د/ سهير محمد التوني }
$$

ا 1 التربية الوقائية. (Protective Education)

هي عبارة عن مجموعه من المفاهيم التوجيهية الصحيحة والتي يجب من خلالها ان يدركها

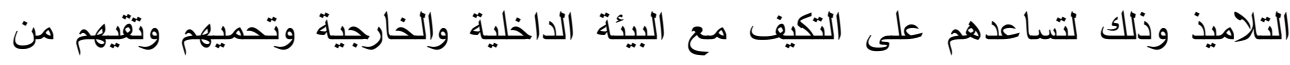

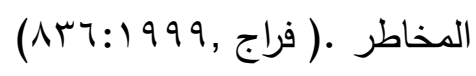

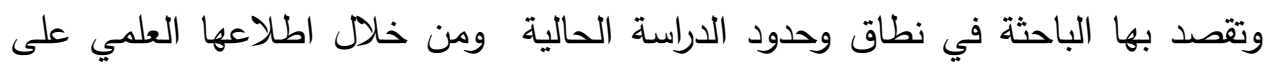

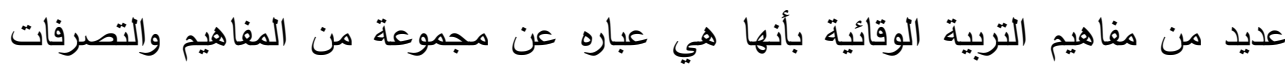
السلوكية والأساليب التربوية السليمة والمتتوعة والتي تثمل على على عدة ابعاد منها النفسية

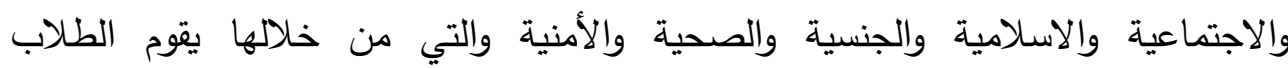

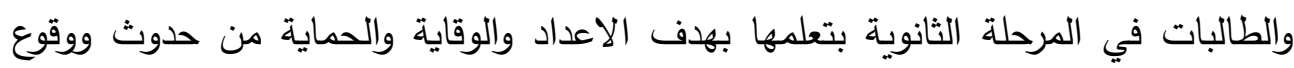

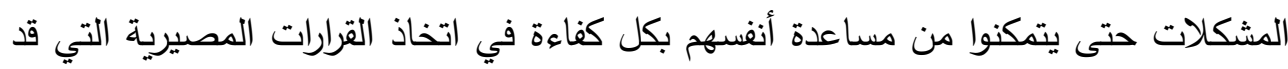

$$
\text { تواجهم في الحياة }
$$

(Psychological empowerment)

هي عبارة عن مجموعة من العوامل والأبعاد الداخلية والتي تحتوي على (التأثير - الاستقلالية

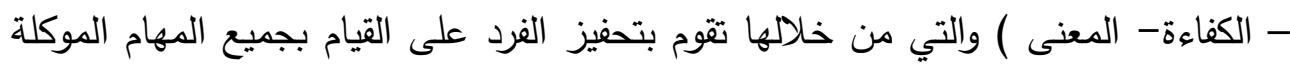

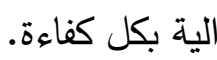

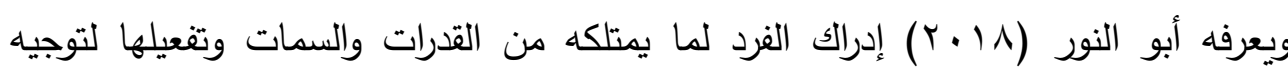
حياته للوجهة الصحيحة ليكون مؤثرا على مستوى حياته الثخصية والمجتمعية. وتقصد به الباحثة في نطاق وحدود الدراسة الحالية ومن خلال اطلاعها العلمي على عديد

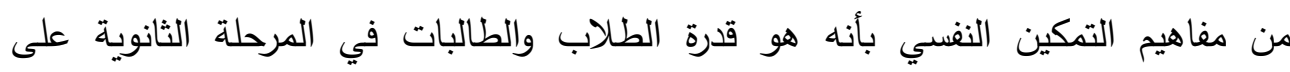
اكتساب وتعلم كم هائل من المعلومات والخبرات الحياتية والمهارات الأساسية التي تمكنهم فلئه

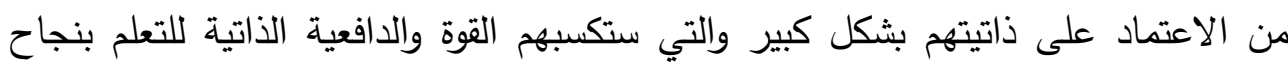
واتخاذ القرارت المناسبة والقدرة على تحمل مسؤولياتهم بكل حريه وجدارة سوآءا في مستتبلهم

$$
\text { اوفي تحصيلهم الدراسي. }
$$


التربية الوقائية و علاقتها بالتمكين النفسي

\section{دراسات سابقة}

المحور الاول : دراسات تناولت التربية الوقائية وعلاقتها بالمتغيرات الاخرى .

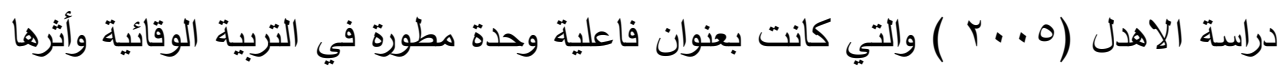
على تحصيل بعض المفاهيم الجغرافية ومواجهة الكوارث الطبيعية والاتجاه نحو مادة الجغرافيا للطالبات في المرحلة المتوسطة في جدة ـ تتمية مفاهيم التربية الوقائية والتصرف وله

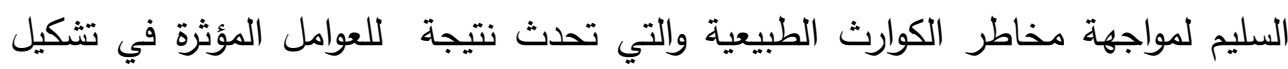
سطح الأرض، ورفع مستوى تحصيل الطالبات في مفاهيم الجغرافية الطبيعية المرتبطة بالبحث، وقد تكونت عينة البحث من ء ـ ا طالبة من الصف الأول المتوسط بمحافظة جدة

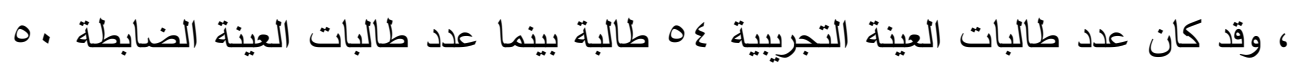
طالبة وتبينت نتائج الدراسة وجود فروق ذات دلالة إحصائية بين متوسطات درجات طالبات

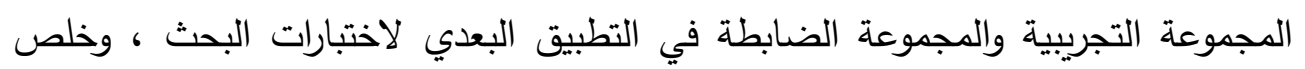
البحث إلى فاعلية الوحدة المطورة في رفع مستوى تحصيل الطالبات في الاختبارات وتعديل اتجاهاتهن

وهدفت دراسة صلاح الفرع (1 . . ب ) الى معرفة اثر البرنامج المحوسب في تتمية مفاهيم التربية الوقائية لدى طلبة الصف التاسع الاساسي واستخدمت المنهج التجريبي البنائي وتكونت العينة من · 9 طالبا وطالبة في الصف التاسع الاساسي بمحافظة رفح ، واظهرت

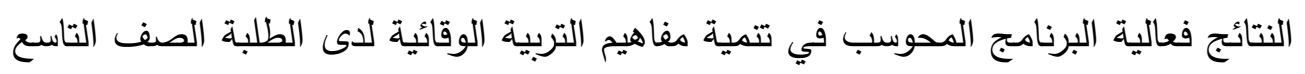

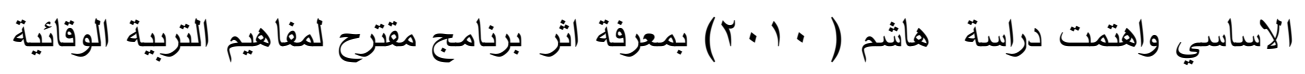

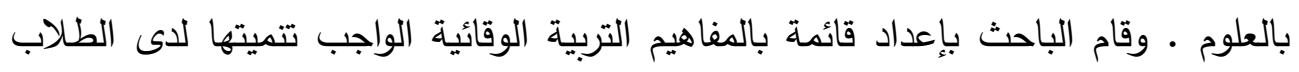
واعد اختبارا لقياس اثر المفاهيم واستخدم المنهج التجريبي وتطبيق الدراسة على عينة مكونة من الV طالبا حيث قسموا الي مجموعتين تجريبية رب والضابطة سب طالبا وتم بناء البرنامج عليهج، وثبتت النتائج اثر الفعالية البرنامج المقترح لتتمية مفاهيم التربية الوقائية

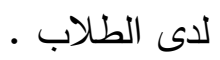

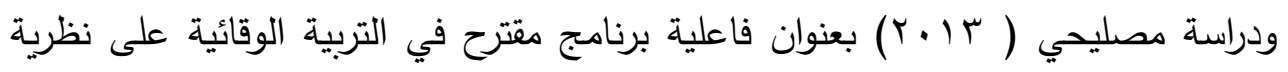
الفهم لتنمية الوعي الوقائي ومهارات حل المشكلات لتلاميذ المرحلة الابتدائية وتهدف الى لى لئه 
أ/ علياء أحمد الحازمي د/ سهير محمد التوني

قياس فاعلية البرنامج المقترح في التربية الوقائية ،والعينة تلاميذ الصف الصفئ الرابع الابتدائي الفئة العمرية من 9-1 1 سنوات وقامت الباحثة بإعداد المقياس الوعي الوقائي واختبار فهم وتعميق المفاهيم المتضمنة للبرنامج المقترح ، وظهر فاعلية برنامج مقترح في التربية الوقائية

على نظرية الفهم لتتمية الوعي الوقائي ومهارات حل المشكلات لتلاميذ المرحلة الابتدائية. دراسة عزب (10 ب ب) بعنوان فاعلية برنامج ارشادي وقائي من الاتصال العاطفي لدى عينة من المعلمات بهدف الوقاية من الانفصال العاطفي والوقوف على أسبابه وتحليلها ومحاولة

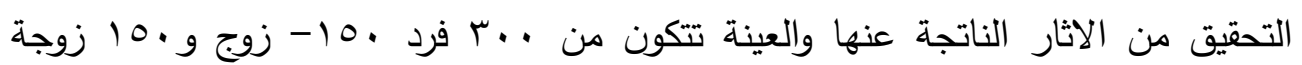
لديهم اضطرابات زوجية ومن ادواتها الدراسة مقياس المستوى الاقتصادي والاجتماعي للأسرة 7 . . r ومقياس الاضطرابات الزواجية من اعداد الباحث والبرنامج الارشادي التكاملي من اعداد الباحث وتستتتج من الدراسة فاعلية الاسلوب الارشادي التكاملي المستخدم في الدراسة. المحور الثاني : دراسات تناولت التمكين النفسي وعلاقتها بالمتغيرات الاخرى .

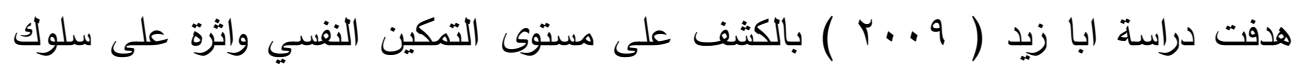
المواطنة التنظيمية لدى العاملين في مؤسسه الضمان الاجتماعي في الاردن ولتحقيق اهدافها تم تبني استبانة مطورة ، والعينة هم العاملين في مؤسسه الضمان الاجتماعي في عمان وعددهم • ب موظفا ، وظهر وجود علاقة بين التمكين النفسي والتوجه الحياتي.

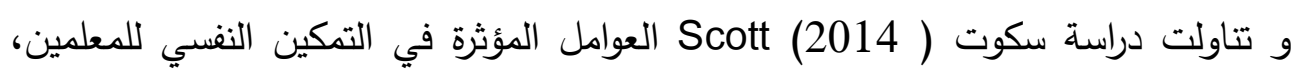
وطبقت على عينة قوامها • 9 معلما ومعلمة، وطبق مقياس سبرايتزر (Spritzer 1995)

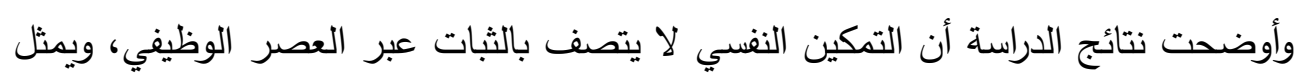
مستوى أقل في المراحل المبكرة والمتأخرة من الحياة الوظيفية للمعلمين، وكثفت الدراسة عن لأن فوائد التمكين النفسي، إذ يؤدي إلى مستوى أعلى من الإلتزام بالعمل والمثابرة ومواجهة

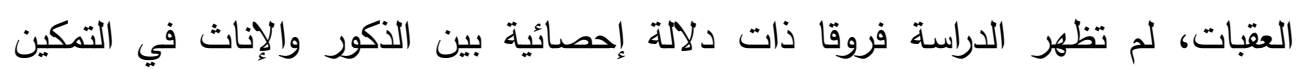
النفسي وبحثت دراسة خليفة(10 · ب) الكثف عن الإسهام النسبي للإدارة الاستراتيجية للموارد البشرية في التمكين النفسي والالتزام الوجداني للمعلمين. وتكونت عينة الدراسة من (سM (ب) معلم ومعلمة، وتمثلت أدوات الدراسة في استبيان الإدارة الاستراتيجية للموارد البشرية، ومقياس 
التربية الوقائية وعلاقتها بالتمكين النفسي

التمكين النفسي، ومقياس الالتزام الوجداني، وأسفرت نتائج الدراسة إلى وجود علاقة إيجابية بين ممارسات الإدارة الاستراتيجية للموارد البشرية وكل من التمكين النفسي والالتزام الوجداني.

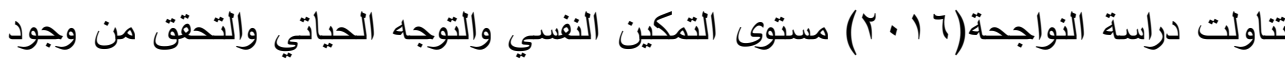
علاقة ارتباطية بين التمكين النفسي والتوجه نحو الحياة، والكشف عن وجود فروق في مستوى التمكين النفسي والتوجه الحياتي لدى عينة الدراسة وفقاً لمتغيرات: (الجنس، وسنوات

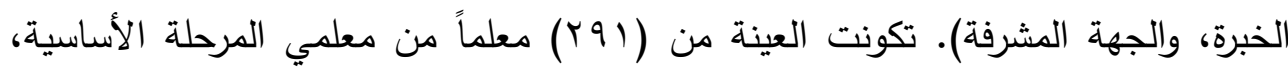
واستخدم الباحث مقياس التمكين النفسي من إعداد سبرايتزر (Spreitzer) 990 ) ومقياس التوجه الحياتي من إعداد شاير وكارفر (Scheier \& Carver) (910)، وأظهرت نتائج

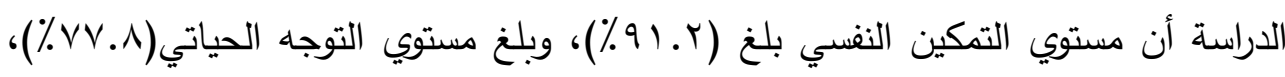
كما اتضح عدم وجود فروق في التمكين النفسي تبعاً لمتغير الجنس ما عدا (بعد التأثير) فقد كانت الفروق لصالح الذكور، وأشارت النتائج إلى وجود فروق في في التمكين النفسي تبعاً

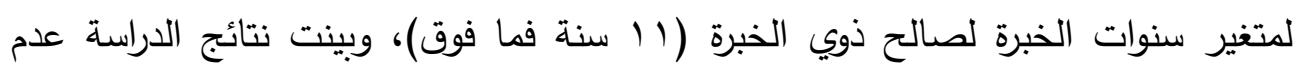
وجود فروق في التمكين النفسي تبعاً لمتغير الجهة المشرفة ما عدا (بعد التأثير) لصالح

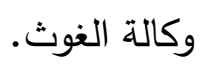

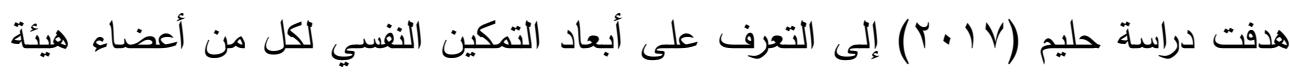
التدريس والهيئة المعونة لهم بجامعة الزقازيق وعلاقتها بالرضا الوظيفي لديهم، كما سعي البحث إلى التعرف على مستوى التمكين النفسي لأعضاء هيئة التدريس والهيئة المعاونة لهم بجامعة الزقازيق، وكذلك التعرف على الفروق بين أعضاء هيئة التدريس والهيئة المعاونة لهم في متغير التمكن النفسي، والتي تعزى إلى عدد من المتغيرات الديموغرافية (النوع، والرتبة

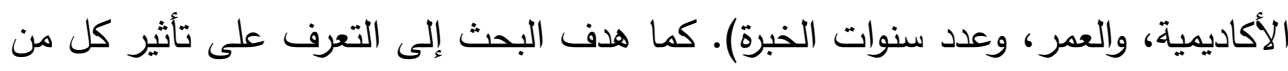

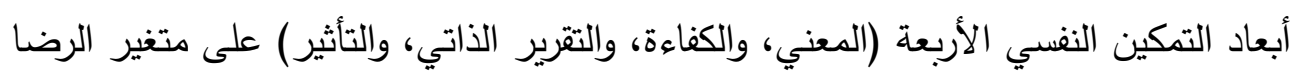
الوظيفي لأعضاء هيئة التدريس والهيئة المعاونة لهم بجامعة الزقازيق.وطبق البحث على الهي

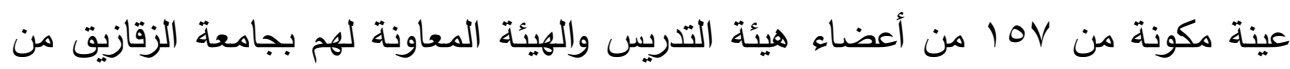

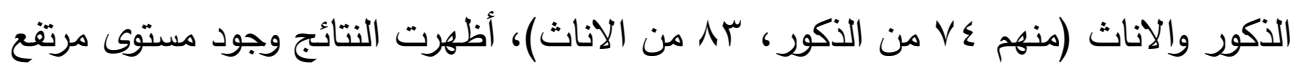




$$
\text { أ/ علياء أحمد الحازمي د/ سهير محمد التوني الإني }
$$

في الابعاد الثلاثة (المعني، الكفاءة، والتقرير الذاتي) لمقياس التمكن النفسي ، وجئئ وجود فروق بين متوسطات درجات أعضاء هيئة التدريس والهيئة المعاونة لهم في بعض أبعاد التمكين النفسي تعزي إلى كل من: (النوع، والرتبة الاكاديمية، والعمر ، وعدد سنوات الخبرة)، في حين

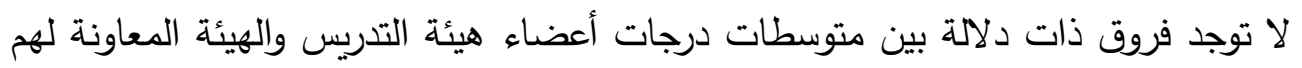
في بعض أبعاد التمكين النفسي الأخرى تعزي إلي كل من (النوع، والرتبة الاكاديمية،

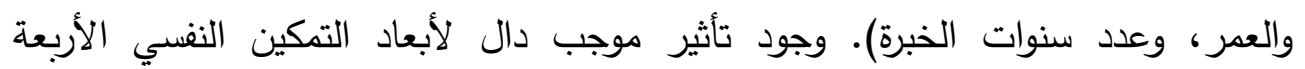
(المعني، والكفاءة، والتقرير الذاتي، والتأثير ) على متغير الرضا الوظيفير. وتوصلت دراسة عبد الفتاح(2018) إلى اختبار نموذج للتأثيرات المباشرة وغير المباشرة لمتغيرات التمكين النفسي والثفقة بالذات والمثابرة الأكاديمية على طلاب المرحلة الثانوية،

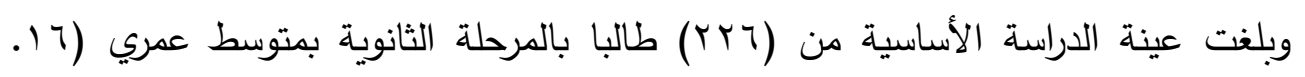

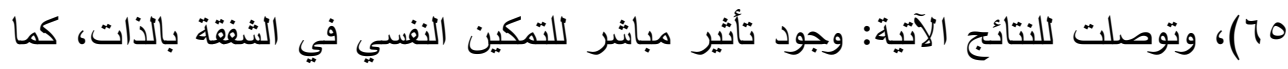
وجد تأثير غير مباشر للتمكين النفسي في المثابرة الأكاديمية عبر المتغير الوسيط الثفقة بالذات.

اشارت دراسة (ابو الهيجاء،2019) الى معرفة أثر التمكين النفسي ودوره في تحسين مستوى الأداء الوظيفي والانتماء التتظيمي في شركات تكنولوجيا المعلومات في الأردن، وقد تكون مجتمع الدراسة من جميع موظفي شركات تكنولوجيا المعلومات في الأردن والبالغ عددهم

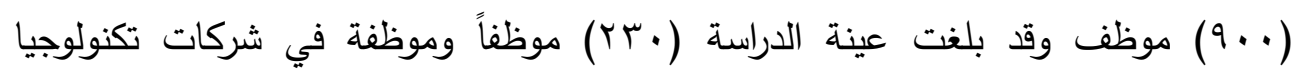
المعلومات. ظهرت نتائج الدراسة وجود أثر إيجابي للتمكين النفسي وأبعاده ككل على الأداء الوظيفي والانتماء التنظيمي. هدفت دراسة ابوليفة(2019) التعرف على دور التمكين النفسي في العلاقة بين أبعاد السلوك الأخلاقي للقيادة (توافر السلوك الأخلاقي، وممارسات السلوك الأخلاقي، وتعزيز السلوك الأخلاقي)، وأبعاد روحانية مكان العمل (العمل الهادف، والإحساس بالمجموعة، والملاءمة

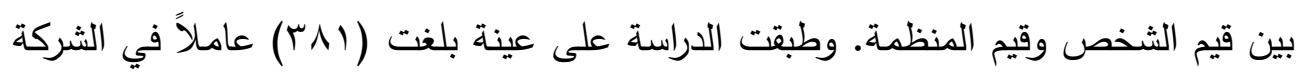
المصرية للاتصالات، توصلت الدراسة إلى وجود علاقة موجبة بين ابعاد السلوك الأخلاقي للقيادة والتمكين النفسي، والى وجود علاقة موجبة بين التمكين النفسي وابعاد روحانية مكان 
التربية الوقائية وعلاقتها بالتمكين النفسي

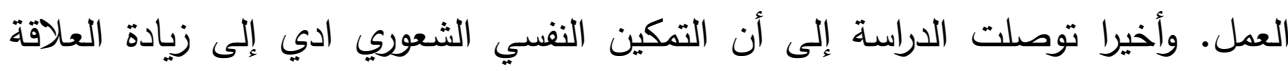
الموجهة بين بعض أبعاد السلوك الأخلاقي للقيادة وابعاد روحانية مكان العمل. ودراسة عيدي (9 ( ب ب) بعنوان التمكين النفسي وعلاقته بالصلابة النفسية لدى المرشدين التربويين وتهدف الى التعرف على التمكين النفسي لدى المرشدين النفسين والتربويين . والعينة هم المسترشدين في المدارس في مدينة بغداد (ن=.0)، وظهر وجود علاقة بين الصدابة الفسية والتمكين النفسي. تعليق على الاراسات السابقة:--

- اهتمت الدراسات السابقة باجراء برامج لتنمية التربية الوقائية مثل دراسة عرفات

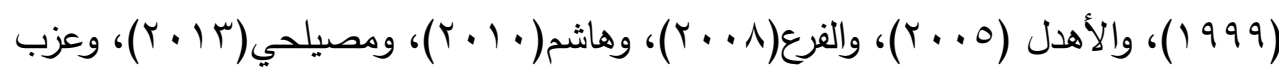

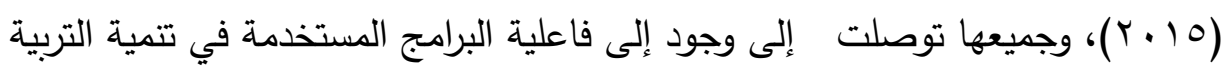
الوقائية لدى عينات مختلفة.

- اهتمت الدراسات السابقة بدراسة العلاقة بين التمكين النفسي وبعض المتغيرات النفسية ، حيث ظهر وجود ارتباط داد بين التمكين النفسي وكل من (الالتزام في العمل ، الالتزام الوجداني، الرضا الوظيفي، الثفقة بالذات، الرضا الوظيفي، السلوك الاخلاقي، الصلابة (النفسية).

- اختلاف نتئج الدراسات فيما يتعلق بالفروق بين الذكور والاناث في التمكين النفسي، حيث

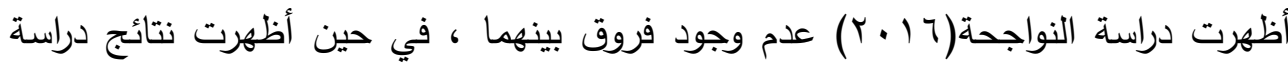

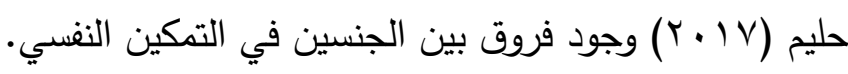
- ندرة الدراسات السابقة التي تتاولت العلاقة بين التربية الوقائية والتمكين النفسي (موضوع الدراسة الحالية) سواء على المستوى العربي أو الاجنبي. ومن خلال عرض الدراسات السابقة والتعليق عليها يمكن صياغة فروض الدراسة كالتالي

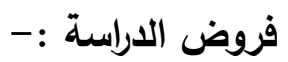
ا - توجد علاقة ارتباطية دالة بين التربية الوقائية وأبعادها الفرعية والتمكين النفسي وأبعاده الفرعية لدى عينه من طلاب المرحلة الثانوية. 
أ/ علياء أحمد الحازمي د/ سهير محمد التوني r- لاتوجد فروق ذات دالة بين الذكور والاناث من طلاب المرحلة الثانوية في التربية الوقائية وأبعاده الفرعية. r- ل ال توجد فروق ذات دالة بين الذكور والاناث من طلاب المرحلة المرحلة الثانوية في التمكين النفسي المنهج والاجراءات عينة البحث:تتكون عينة البحث من ( . . ب) طالبا وطالبة من طلاب المرحلة الثانوية بمدينة

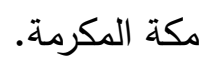
والجدول التالي يوضح توزيع أفراد العينة حسب الجنس:

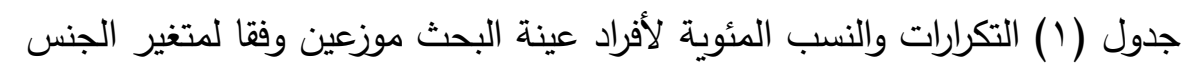

\begin{tabular}{|c|c|c|}
\hline النسبة المئوية \% & العدد & الجنس \\
\hline$\% .0$ & 10. & ذكر \\
\hline$\%$ & 10. & أنثي \\
\hline$\% 1 \ldots$ & $r$. & المجموع \\
\hline
\end{tabular}

يلاحظ من الجدول السابق تساوي أفراد عينة البحث من طلاب وطالبات المرحلة الثانوية

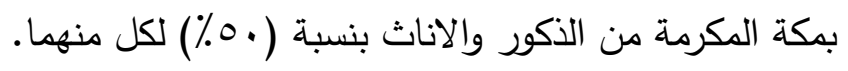

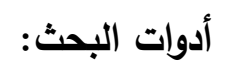
قامت الباحثة باستخدام الادوات التالية: أولا: مقياس التربية الوقائية إعداد: الباحثة لبانة البانة بني المقياس على سبعة أبعاد وهي على النحو التالي: البعد الأول التربية الصحية: هي عملية مساعدة الطلاب والطالبات في المدرسة على إدراك الوعي الصحي وتكوين اتجاهات صحية وقائية سليمة واتباع السلوك الصحي في حياته اليومية بما يحافظ على صحته وصحه اسرته وصحة مجتمعة ويمثل هذا البعد (V) عبارات. البعد الثاني التربية النفسية: هي عبارة عن مجموعه من الخدمات التي تقدمها المدرسة لمساعدة وتثثيف الطلاب والطالبات وتبصيرهم بأهم المشكلات والاضطرابات النفسية التي يواجهونها في هذه المرحلة مما تعيق مسار تحصيلهم الدراسي ويمثل هذا البعد (9) عبارات. 


\section{التربية الوقائية وعلاقتها بالتمكين النفسي}

البعد الثالث التربية الجنسية: هي مساعدة الطلاب والطالبات على اكتساب وتكوين اتجاهات صحيحه وسليمة حول الجنس والهوية الجنسية وذلك بهدف حمايتهم من أي استغلال او اغتصاب او الشروع في علاقات غير شرعية مما ينجم عنها مخاطر انتقال الامراض الجنسية ويمثل هذا البعد (V) عبارات.

البعد الرابع التربية الاجتماعية: هي مجموعه من القيم والمعارف التي تود المدرسة اكسابها للطلاب والطابات بشتى أنواع الوسائل والطرق بحيث يكونون قادرين على التكيف والتعامل السليم مع ذاتهم ومع مجتمعهم الصغير (الصف-المدرسة) او مع مجتمعة الكبير ويمثل هذا البعد (7) عبارات.

البعد الخامس التربية القانونية: هي جهود تبذل للتعريف وتبصير الطلاب والطالبات بأهمية التعرف على ماهية ولوائح المواظبة والانضباط والحقوق والواجبات الأساسية اتجاه افراد المجتمع وذلك لضمان عدم السلب وانتهاك الحقوق ويمثل هذا البعد (0) عبارات. البعد الساد التربية الأمنية: هي ترسيخ وتعليم الطلاب والطالبات المفاهيم الأمنية وكيفية المحافظة على الهوية الوطنية وغرس فيهم حب الوطن من خلال الحماية والدفاع عنه وعن ممتلكاته من قبل الأشرار ويمثل هذا البعد (7) عبارات. البعد السابع التربية الإسلامية: وهي اعداد المسلم اعداد كاملا من جميع النواحي وفي جميع مراحل نموه لحياة الدنيا والاخرة في ضوء المبادئ والقيم وطرق التربية التي جاء بها الإسـلام وأيضا هي بناء الانسان بناءا متكاملا متوازنا جسميا وعاطفيا واجتماعيا وخلقيا وجماليا وانسانيا كما يكون هذا الانسان بشخصيته لبنه حيه فعاله في بناء مجتمعه ويمثل هذا البعد (V) وبناء على ما سبق تم صياغة (گV) عبارة منها (rr) عبارة إيجابية و (10) عبارات سلبية. ويظهر الجدول التالي توزيع العبارات حسب نوعها. 
أ/ علياء أحمد الحازمي د/ سهير محمد التوني جدول رقم (Y) توزيع عبارات مقياس التربية الوقائية

\begin{tabular}{|c|c|c|}
\hline العبار ات السالبة & العبار ات الموجبة & البعد \\
\hline 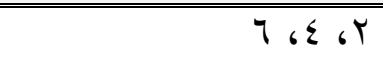 & 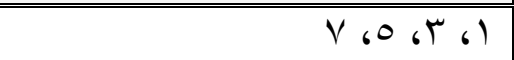 & التربية الصحية \\
\hline $1761061 \leqslant 6116961$ & 1461161. & التربية النفسية \\
\hline 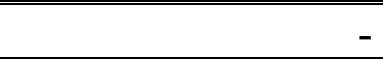 & 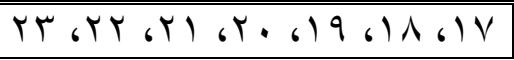 & التربية الجنسية \\
\hline TA 6YY 6Y & Y9, TV 6 YO & التربية الاجتماعية \\
\hline (IT) & $r \leqslant 6 r$ r & التربية القانونية \\
\hline- & 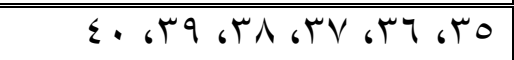 & التربية الأمنية \\
\hline$\varepsilon V$ & 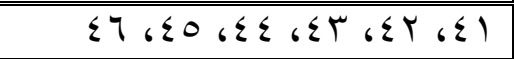 & التربية الإسلامية \\
\hline
\end{tabular}

\section{صدق مقياس التربية الوقائية:}

للتحقق من صدق المقياس تم عرضه في صورته المبئية على مجموعة من أساتذة الجامعات المتخصصين في علم النفس وذلك لإبداء رأيهم ، وفي ضوء توجيهات المحكمين قامت الباحثة بإعادة صياغة بعض العبارات التي أجمع عليها المحكمون على ضرورة وإثى تعديلها لكي يكون المقياس صادقا تحكيميا. وقد أتفق المحكمون على أن المقياس يقيس التربية الوقائية بعد إدخال التعديلات المقترحة من قبلهم عليه. واعتبرت موافقة المحكمين على صلاحية الاختبار للتطبيق على البيئة السعودية بعد إجراء التعديلات بمثابة الصدق الظاهري للمقياس. وبناء على ما سبق فقد تم توزيع مستويات الاستجابة على عبارات المقياس وأوزانها المقابلة وفقا للجدول الموضح أدناه.

جدول (ب) توزيع مستويات الاستجابة على عبارات مقياس التربية الوقائية وأوزانها المقابلة

\begin{tabular}{|c|c|c|c|c|c|}
\hline \multicolumn{6}{|c|}{ مستويات الاستجابة الخمسة } \\
\hline ابدا & نادر ا & أحيانا & غالبا & دائما & نوع العبار ات \\
\hline 1 & $\bar{r}$ & $\bar{r}$ & $\varepsilon$ & 0 & العبار ات الإيجابية \\
\hline 0 & $\varepsilon$ & $\Gamma$ & $\bar{Y}$ & 1 & العبار ات السلبية \\
\hline
\end{tabular}

في ضوء التدريج الخماسي السابق وعدد عبارات المقياس فإن العلامة القصوى الممكنة

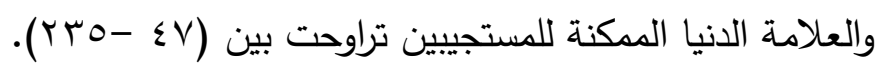




\section{التربية الوقائية وعلاقتها بالتمكين النفسي}

بعد إجراء التعديلات المقترحة من قبل المحكمين، طبق المقياس في صورته المبدئية على العى

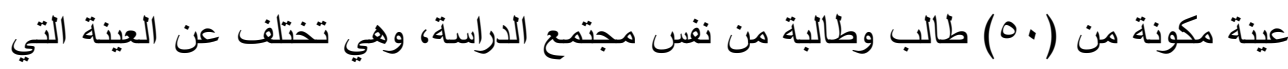
طبقت عليها التجربة وأظهر المقياس على العينة الاستطلاعية وضوح الصياغة اللغوية

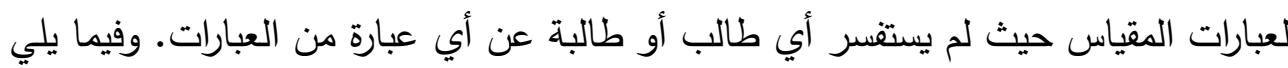

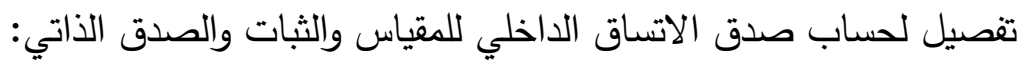

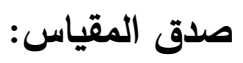

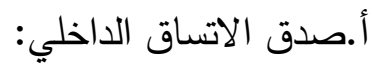
ولحساب صدق الاتساق الداخلي تم حساب معاملات الارتباط بيرسون بين درجات كل عبارة

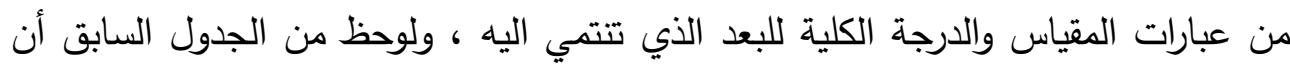

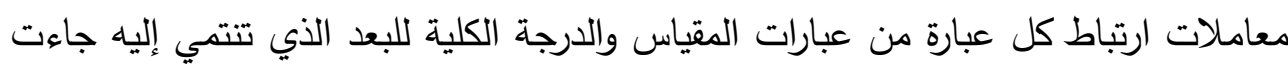

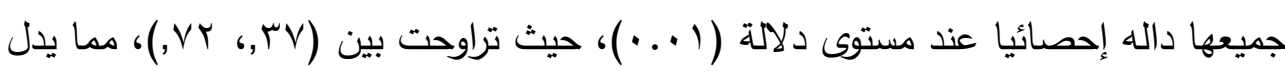
على توافر درجة عالية من صدق الاتساق الداخلي للمقياس.

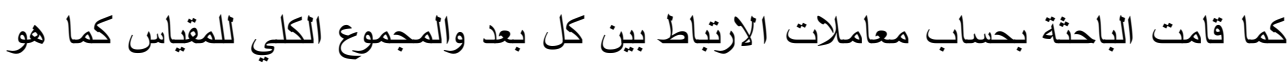

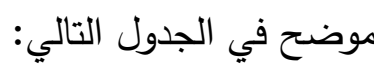
وتبين أن قيم معاملات الارتباط بين مجموع درجات كل بعد من الابعاد الرئيسية السبعة

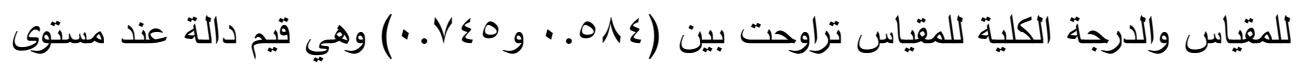

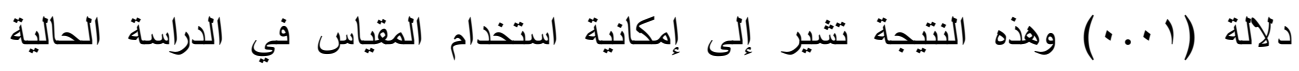

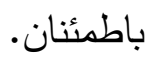

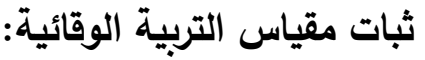

للتحقق من ثبات المقياس استخدمت الباحثة معادلة ألفا كرونباخ.

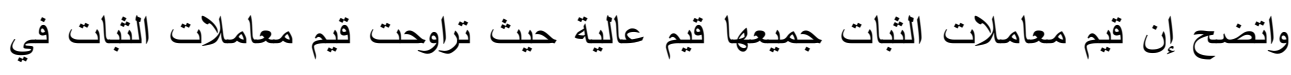

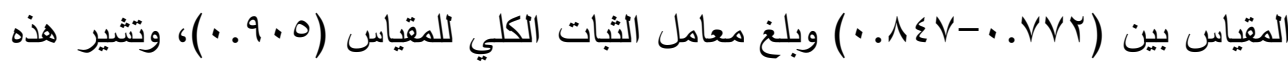

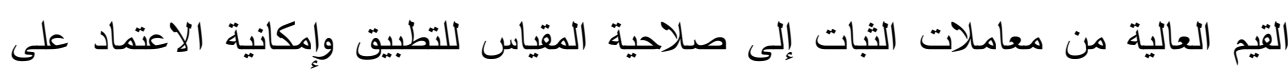
نتائجها والوثوق بها. 
أ/ علياء أحمد الحازمي د/ سهير محمد التوني ثانيا: مقياس التمكين النفسي إعداد: الباحثة أدمازئ بني المقياس على سبعة أبعاد وهي على النحو التالي: البعد الأول الجدارة (الكفاءة): هي اعتقاد وايمان داخلي لدى الطى الطلاب والطالبات بأنهم يمتلكون قدرات وامكانيات ومهارات عالية تمكنهم من مواصلة تحصيلهم الدراسي بكل كفاءة وجدارة مميزة ويمثل هذا البعد (0) عبارات. البعد الثاني المعنى (المغزى والاهمية): هو شعور الطلاب والطالبات بأهمية اكمال التعليم والدراسة لأنها تعطي للفرد قيمة وفائدة في المجتمع ومنها تتحقق الأهداف المرجوة ويمثل هذا لتول البعد (0) عبارات. البعد الثالث الاستقلالية (تقرير المصير): هو امتلاك الطلاب والطالبات الاستقلالية والحرية

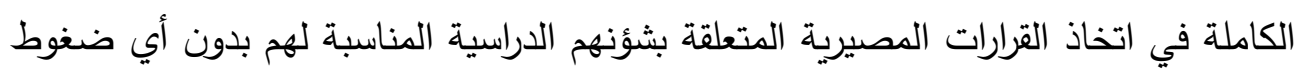
او قيود عليهم ويمثل هذا البعد (0) عبارات. البعد الرابع التأثير : هو شعور الطلاب والطالبات بأنهم يمتلكون التهات المهارات والقدرات التي

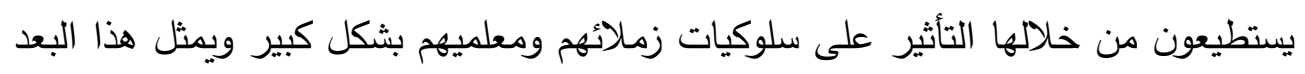
(0) (0) عبارات. (1) (1)

البعد الخامس التحفيز الذاتي: هي شحن وتقوية مشاعرك واحاسيسك التي تقودك الى تحقيق اهدافك او تسهل عليك القيام بذلك ويمثل هذا البعد (0) عبارات. البعد الساد الإيجابية والتفاؤل: هي نظرة استبشار نحو المستقبل تجعل الفرد يتوقع الأفضل وينتظر حدوث الخير ويرنو الي النجاح ويستبعد ماعدا ذلك ويمثل هذا البعد (0) عبارات. البعد السابع الدافعية للتعلم: هي رغبة داخلية لدى المتعلم تدفعه الى الانتباه الى الموقف التعليمي والقيام بنشاط موجه والاستمرار في هذا النشاط حتى يتحقق التعلم كهدف للمتعلم.

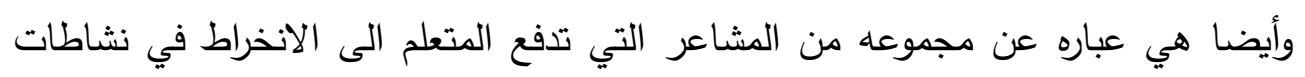
التعلم التي تؤدي الى بلوغه الأهداف المنشودة وهي ضرورة أساسيه لحدوث التعلم ويمثل هذا البعد (ع) عبارات. 
التربية الوقائية وعلاقتها بالتمكين النفسي

وبناء على ما سبق تم صياغة (ءץ) جميعها عبارات إيجابية ويظهر الجدول التالي توزيع

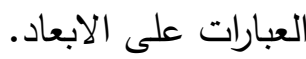

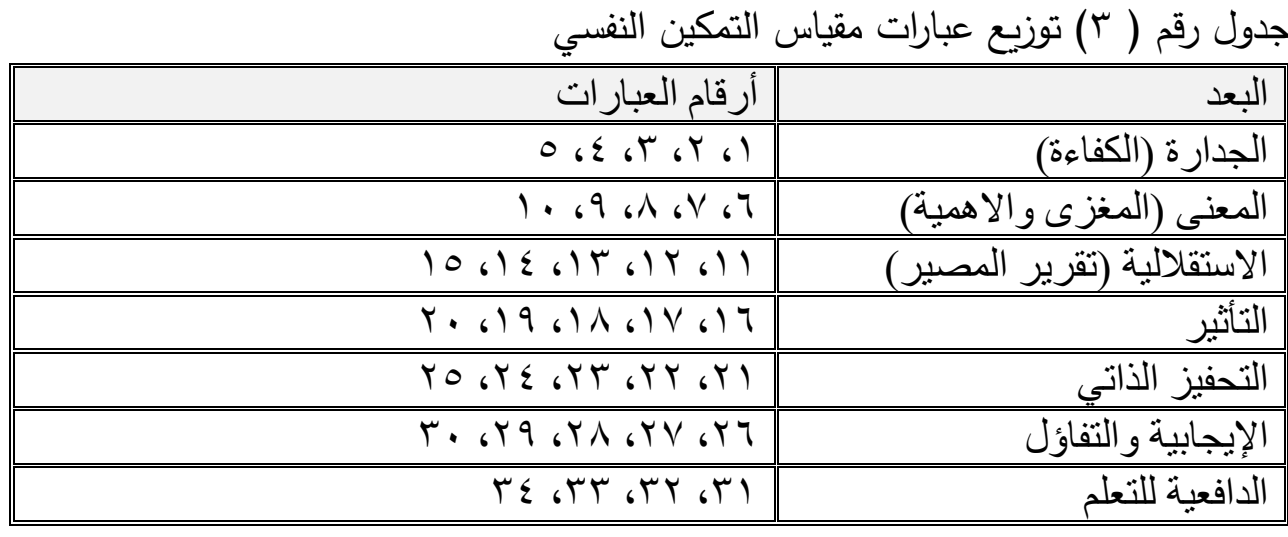

صدق مقياس التمكين النفسي:

للتحقق من صدق المقياس تم عرضه في صورته المبدئية على مجموعة من أساتذة الجامعات المتخصصين في علم النفس وذلك لإبداء رأيهح ، وفي ضوء توجيهات المحكمين قامت الباحثة بإعادة صياغة بعض العبارات التي أجمع عليها المحكمون على ضرورة تعديلها لكي يكون المقياس صادقا تحكيميا. وقد أتفق المحكمون على أن المقياس يقيس التمكين النفسي بعد إدخال التعديلات المقترحة من قبلهم عليه. واعتبرت موافقة المحكمين على صلاحية الاختبار للتطبيق على البيئة السعودية بعد إجراء التعديلات بمثابة الصدق الظاهري للمقياس.وتم الاجابة على عبارات المقياس بالاختيار من (دائما، غالبا، أحيانا، نادرا، أبدا) وتأخذ درجات(0، ع، ب، r، () التجربة الاستطلاعية لمقياس التمكين النفسي: بعد إجراء التعديلات المقترحة من قبل المحكمين، طبق المقياس في صورته المبدئية على عينة مكونة من (•0) طالب وطالبة من نفس مجتمع الدراسة، وهي تختلف عن العينة التي طبقت عليها التجربة وأظهر المقياس على العينة الاستطلاعية وضوح الصياغة اللغوية لعبارات المقياس حيث لم يستفسر أي طالب أو طالبة عن أي عبارة من العبارات. وفيما يلي تفصيل لحساب صدق الاتساق الداخلي للمقياس والثبات والصدق الذاتي: 
أ/ علياء أحمد الحازمي د// سهير محمد التوني صدق مقياس التمكين النفسي: صدق الاتساق الداخلي:ولحساب صدق الاتساق الداخلي تم حساب معاملات الارتباط بيرسون بين درجات كل عبارة من عبارات المقياس والدرجة الكلية للبعد الذي تتتمي اليه

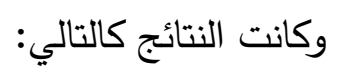
ولوحظ أن معاملات ارتباط كل عبارة من عبارات المقياس والدرجة الكلية للبعد الذي تتنمي

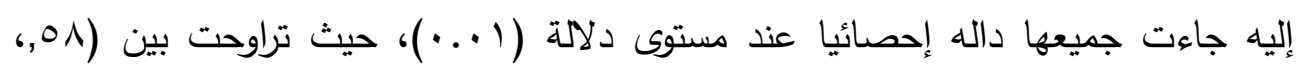
ד^,)، ما يدل على توافر درجة عالية من صدق الاتساق الداخلي للمقياس.

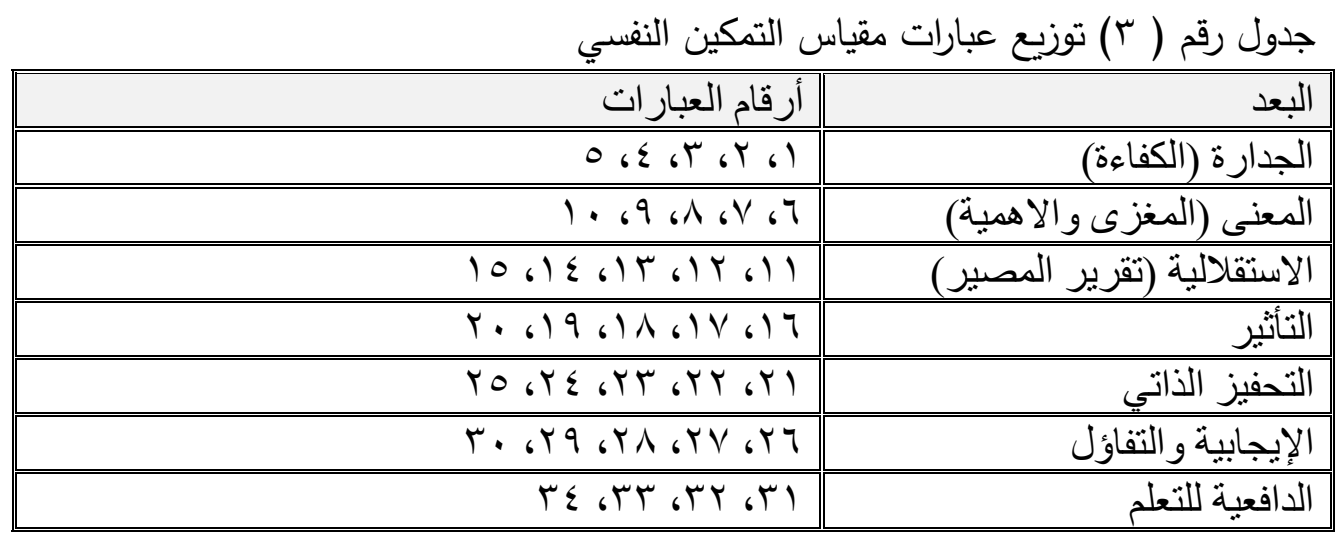

صدق مقياس التمكين النفسي:

للتحقق من صدق المقياس تم عرضه في صورته المبئية على مجموعة من أساتذة الجامعات المتخصصين في علم النفس وذلك لإبداء رأيهر ، وفي ضوء توجيهات المحكمين

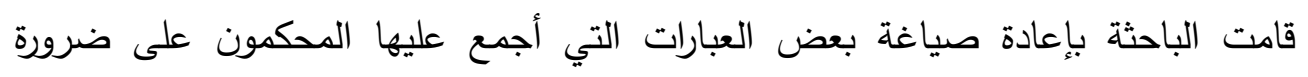
تعديلها لكي يكون المقياس صادقا تحكيميا. وقد أتقق المحكمون على أن المقياس يقيس التمكين النفسي بعد إدخال التعديلات المقترحة من قبلهم عليه. واعتبرت موافقة المحكمين

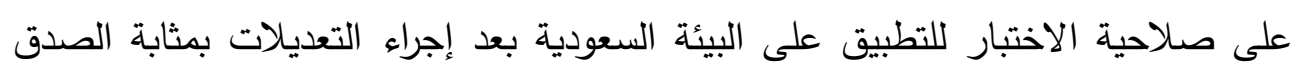
الظاهري للمقياس.وتم الاجابة على عبارات المقياس بالاختيار من (دائما، غالبا، أحيانا،

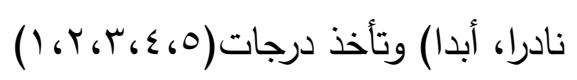

$r$. مجلة بحوث كلية الآداب 


\section{التربية الوقائية وعلاقتها بالتمكين النفسي}

التجربة الاستطلاعية لمقياس التمكين النفسي:

بعد إجراء التعديلات المقترحة من قبل المحكمين، طبق المقياس في صورته المبدئية على عينة مكونة من (•0) طالب وطالبة من نفس مجتمع الدراسة، وهي تختلف عن العينة التي طبقت عليها التجربة وأظهر المقياس على العينة الاستطلاعية وضوح الصياغة اللغوية لعبارات المقياس حيث لم يستفسر أي طالب أو طالبة عن أي عبارة من العبارات. وفيما يلي تفصيل لحساب صدق الاتساق الداخلي للمقياس والثبات والصدق الذاتي: صدق مقياس التمكين النفسي: صدق الاتساق الداخلي:ولحساب صدق الاتساق الداخلي تم حساب معاملات الارتباط بيرسون بين درجات كل عبارة من عبارات المقياس والدرجة الكلية للبعد الذي تتنمي اليه

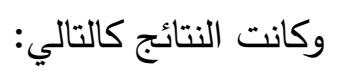

ولوحظ أن معاملات ارتباط كل عبارة من عبارات المقياس والدرجة الكلية للبعد الذي تتنمي إليه جاءت جميعها داله إحصائيا عند مستوى دلالة (1 (.).) حيث تراوحت بين (01,، ד^^,)، مما يدل على توافر درجة عالية من صدق الاتساق الداخلي للمقياس. ند مستوى دلالة (1 (..) وهذه النتيجة تشير إلى إمكانية استخدام المقياس في الدراسة الحالية باطمئنان. ثبات مقياس التمكين النفسي: للتحقق من ثبات المقياس استخدمت الباحثة معادلة ألفا كرونباخ، واتضح أن قيم معاملات الثبات جميعها قيم عالية حيث تراوحت قيم معاملات الثبات في المقياس بين (.vo... .-

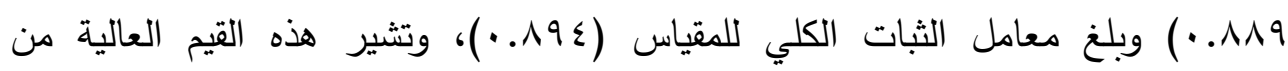
معاملات الثبات إلى صلاحية المقياس للتطبيق نتائج الاراسة ومناقشتها :-

$$
\text { الفرض الأول: وينص علي }
$$

توجد علاقة ارتباطية دالة بين التربية الوقائية وأبعادها الفرعية والتمكين النفسي وأبعاده الفرعية لاى عينه من طلاب المرحلة الثانوية. 
أ/ علياء أحمد الحازمي د/ سهير محمد التوني لبحث الفرض الأول من فروض الدراسة تم استخدام معامل ارتباط بيرسون لإيجاد العلاقة

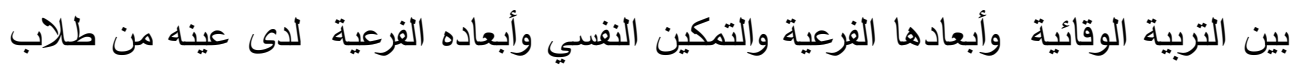
وطالبات المرحلة الثانوية ويوضح الجدول رقم (ع) النتائج: جدول (ع) معامل الارتباط بين التربية الوقائية وأبعادها الفرعية والتمكين النفسي وأبعاده الفرعية لدى عينة الدراسة

\begin{tabular}{|c|c|c|c|c|c|c|c|c|}
\hline التربية & التربية & الأمنية & القانونية & الاجتمباعية & الجنسية & التفسية & التربية & \\
\hline$* *,, \leq 0$. & $* *$, , rVo & $* *,, r q$. & $* *, \mu, \tau$ & $* *, \pi, \tau$ & $* *,, r, o$ & **, rו, & *, TrE & (الجفارة) \\
\hline$* *, 011$ & $* *,, q_{q}$ & $* *$, r人q & **, r r & $* *,, r \leq 1$ & **, rq & $* *,, Y \wedge \vee$ & $*, Y I T$ & (المغنى \\
\hline$* *,, \leqslant 00$ & **, זчו & $* *,, r \leq r$ & $* *,, Y Y V$ & $* *,, r 97$ & **, r, & $* *,, Y \vee \neg$ & $* *,, Y, V$ & الاستقلالبة \\
\hline "**, rqV & (**, , 170 & "**, & (**.,19. & "**., YY. & "**, r.V & "**, & "**, YrY & التأثثر \\
\hline$* *, \leq\rceil 70$ & $* *$, , YTV & **, r & $* *, r, q$ & 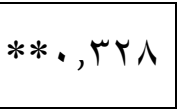 & **, ro. & $* *,, \nvdash q 7$ & $* *, r V$. & التاتحفيز \\
\hline **, r *, & $* *$, rov & וTr, •** & **, • & $* *,, \pi q q$ & $* *,, \leqslant 00$ & עrז, ,** & **, , YO. & والإيجابية \\
\hline$* *,, \pi 90$ & **, & $* *, r q 1$ & $* *$, , ror & $* *,|\wedge|$ & $* *,, r q \wedge$ & $* *$, , ү०ᄉ & $* *, 1 \wedge 0$ & اللتعلم \\
\hline$* *, 7, \ldots$ & **, , & $* *,, \leq r V$ & $* *,, \pi \circ q$ & $* *,, \Pi \wedge \varepsilon$ & $* *,, \leq 71$ & **, rq & **, r, r & كقياس \\
\hline
\end{tabular}

"وجود دلالة عند مستوى 0. . .

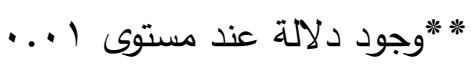

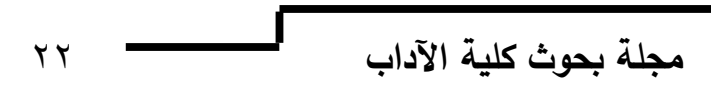


التربية الوقائية وعلاقتها بالتمكين النفسي

يتضح من الجدول السابق وجود ارتباط دال بين التربية الوقائية وأبعادها الفرعية، والتمكين

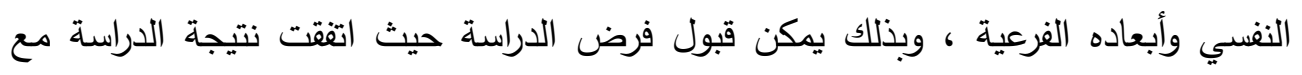
الفرض الحالي، ومن خلال عرض الدراسات السابقة يظهر ندرة في الدراسات التي تتاولت العلاقة بين المتغيرين.

وتوضح الباحثة أن للتربية الوقائية دورا هاما في التمكين النفسي للطلاب ، حيث أن التمكين النفسي يجعل الفرد قادرا على توظيف وتتميه ما لديه من قدرات واستعدادات نفسيه تجعله التهيه قادرا على التحكم واتخاذ القرارات المناسبة في مواقف الحياة المختلفة. وكما أن التربية الوقائية والتمكين النفسي لدى الطلاب والطالبات والتطرق الى معرفه الابعاد واحتياجات الطلاب والطالبات النمائية تساعد في اعدادهم لمواجهة المشكلات والتصدي لها وخصوصا في مرحله المراهقة. وقد أولت العديد من الدراسات والأبحاث أهمية كبيرة في الآونة الأخيرة لموضوع التربية الوقائية والتمكين النفسي لما له من اهميه في زيادة التطور والرقي للى الطلاب، كما تتوكد على ان التربية الوقائية لها تأثير كبير و مهم على توعيه الأفراد

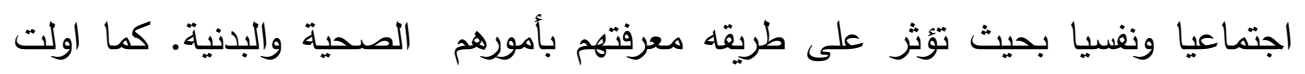

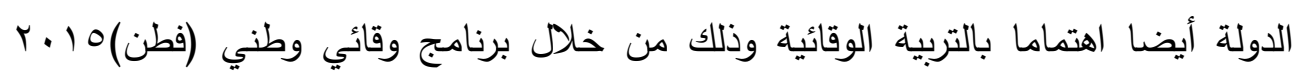

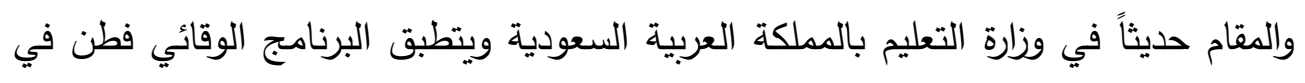
جميع مدارس المملكة للطلاب والطالبات والذي يعنى بتنمية مهارات الطلاب والطالبات الشخصية والاجتماعية لوقاية أبنائنا وتعزيز القيم الاجتماعية والأخلاقية في إطار تعاليم الدين الإسلامي ونشر الوعي الصحي والاجتماعي والنفسي. كما يتضح أن التربية الوقائية هي مجموعة من القيم والمهارات والمعارف العلمية والخبرات التي يجب على ولى الطالب ان اندي يكون ملما بها ومعد لها جيدا من خلال التربويين الناجحين والمؤثرين فيقومون بتعليمهم واكسابهم تلك الاتجاهات التي تساعدهم على ادارة حياتهم وحمايتهم من المخاطر الناجمة عن عدم فهمهم وادراكهم لمجريات الحياة، وبالتالي يجب غرسها منذ النشئ حتي تساعدهم على التمكين النفسي. 
أ/ علياء أحمد الحازمي د/ سهير محمد التوني الفرض الثاني: وينص علي

لا توجد فروق ذات دالة بين الذكور والاناث من طلاب المرحلة الثانوية في التربية

الوقائية وأبعادها الفرعية.

لبحث هذا الفرض قامت الباحثة باستخدام اختبار (ت) لتحديد وجود فروق ذات دلالة إحصائية بين متوسطي درجات مقياس التربية الوقائية بأبعاده تعزى لمتغير الجنس (ذكر، أنثى) لدى عينة الدراسة من طلاب وطالبات المرحلة الثانوية، وكانت النتائج كالتالي: جدول (0) نتائج تحليل اختبار (ت) لتحديد دلالة الفروق بين متوسطي درجات مقياس

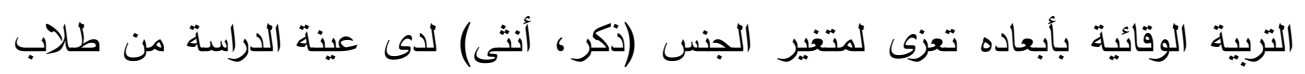
وطالبات المرحلة الثانوية

\begin{tabular}{|c|c|c|c|c|c|c|}
\hline مستوى & قيمة (ت) & الانحر اف المعياري & الحستوسطي & العدد & الجنس & 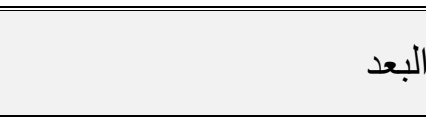 \\
\hline \multirow{2}{*}{$\cdot, \Lambda \cdot r$} & \multirow{2}{*}{, YO. } & $T, 77 \varepsilon$ & $r M, \wedge r$ & 10. & ذكر & \multirow{2}{*}{ لتربية الصحية } \\
\hline & & r,YOV & $T M, V Y$ & 10. & أنتى & \\
\hline \multirow{2}{*}{$\cdot, 707$} & \multirow{2}{*}{$\cdot, \leq \leqslant 0_{-}$} & $7,1 \wedge r$ & ro, Yo & 10. & ذكر & \multirow{2}{*}{ التربية النفسية } \\
\hline & & $0,\{71$ & $r 0,00$ & 10. & أنثى & \\
\hline \multirow{2}{*}{$\cdot, .97$} & \multirow{2}{*}{1,779} & $\varepsilon, V \cdot$ & $r \cdot, \ldots$ & 10. & ذكر & \multirow{2}{*}{ التربية الجنسية } \\
\hline & & $r, \leq \leq \varepsilon$ & $r \cdot, V T$ & 10. & أنتى & \\
\hline \multirow{2}{*}{$\cdot, 171$} & \multirow{2}{*}{$1, \varepsilon \cdot \tau_{-}$} & $r, v \leq 7$ & $r \mu, r \Lambda$ & 10. & ذكر & \multirow{2}{*}{ التربية الاجتماعية } \\
\hline & & $\Gamma, Y) \leq$ & $T r, 90$ & 10. & أنتى & \\
\hline \multirow{2}{*}{$\cdot, \cdot \leq r$} & \multirow{2}{*}{$r, \cdot r \cdot=$} & $r, V 70$ & 11,79 & 10. & ذكر & \multirow{2}{*}{ التربية القانونية } \\
\hline & & $r, r \cdot \Lambda$ & 19,01 & 10. & أنثى & \\
\hline \multirow{2}{*}{$\cdot, \cdots 9$} & \multirow{2}{*}{$r, T \backslash 7$} & $\varepsilon, \leqslant \leqslant 7$ & $r T, V T$ & 10. & ذكر & \multirow{2}{*}{ التربية الأمنية } \\
\hline & & (E,TrV & $r Y, \Sigma T$ & 10. & أنثى & \\
\hline \multirow{2}{*}{ מז", } & \multirow{2}{*}{$r, \mid r \Lambda_{-}$} & $r, 0.7$ & $r \cdot, T r$ & 10. & ذكر & \multirow{2}{*}{ التربية الإسلامية } \\
\hline & & $r, 1 \wedge r$ & $r 1, \leq 0$ & 10. & أنثى & \\
\hline \multirow{2}{*}{ • } & \multirow{2}{*}{$\cdot, \wedge T V_{-}$} & $19, r \cdot 1$ & $110,0 \mathrm{r}$ & 10. & ذكر & \multirow{2}{*}{ الدرجية الكلية لمقياس التربية } \\
\hline & & $17,9 \leq$. & INV,rs & 10. & أنتى & \\
\hline
\end{tabular}


التربية الوقائية وعلاقتها بالتمكين النفسي

يتضح من الجدول السابق عدم وجود فروق بين الذكور والاناث في التربية الوقائية وأبعادها النفسية ، ويتضح مما سبق قبول الفرض الصفري المتفق مع نتائج الدراسة الحالية وعند عرض الدراسات السابقة وجد أنها لم تتناول الفروق في التربية الوقائية والتي تعزى إلى متغير الجنس، ويمكن رجوع ذلك إلى أنه عينة الدراسة سواء من الطلاب أو الطالبات يتعرضون لنفس الظروف البيئية ويعيشون بنفس المنطقة السكنية ويتعلمون بنفس المدارس الحكومية مما حال إلى ظهور فروف بينهما في التربية الوقائية، كما أن التربية الوقائية تهدف الى المام الطالب بالمهارات والمفاهيم والاتجاهات والقيم التي من خلالها تحميهم وتقييهم من الوقوع في المشكلات وهذا يتعلمه الذكور والاناث في مدارسهر من نفس هن

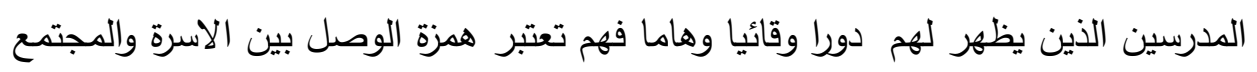

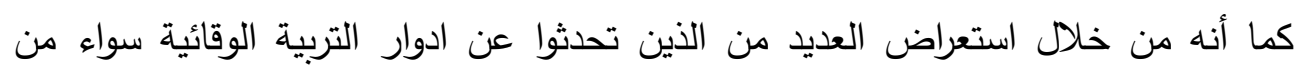
الاسرة اوالمدرسة فهذا كله ينعكس على تتمية وصيانة افراد المجتمع وان هناك منهج رباني يكفل ويضمن للأفراد كيفية التعامل والحفاظ على النفس البشرية من الانحرافات والسلوكيات الشاذة واكسابهم بعض من التوجيهات والافكار والمعلومات التي تقييهم وتنمي لديهم الوعي

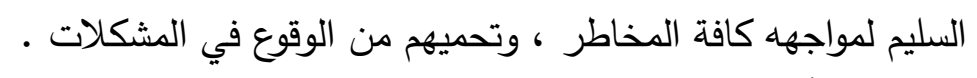

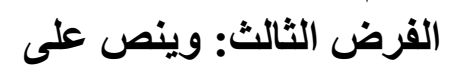
لا توجد فروق ذات دالة بين الأكور والاناث من طلاب المرحلة المرحلة الثانوية في

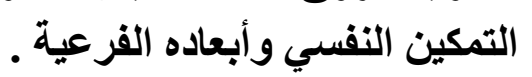

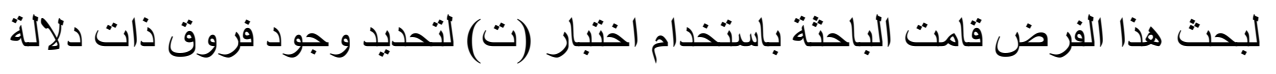

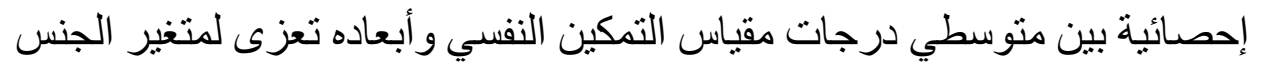
(ذكر ، أنثى) لاى عينة الدر اسة من طلاب وطنئ دالبات المرحلة الثانوية، وكانت النتائج

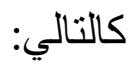


أ/ علياء أحمد الحازمي د/ سهير محمد التوني

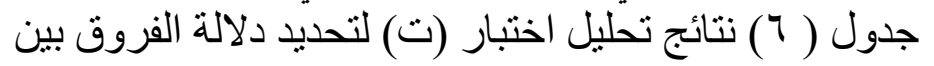

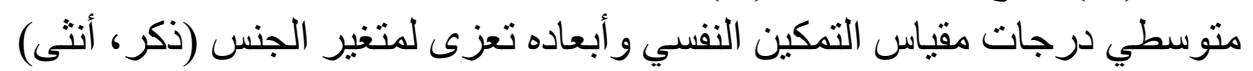
لاى عينة الدر اسة من طلاب وطالبات المرحلة الثانوية

\begin{tabular}{|c|c|c|c|c|c|c|}
\hline الدلالة & ق قيمة & الالانحر افياري & الحسابي & العدد & الجنس & البعد \\
\hline \multirow{2}{*}{$\cdot, \lambda 11$} & \multirow{2}{*}{$\cdot, r \leqslant \cdot-$} & $r, 070$ & $r \cdot, O Y$ & 10. & ذكر & \multirow{2}{*}{ الجدارة (الكفاءة) } \\
\hline & & $r, 7 r^{\prime}$ & $r \cdot, T)$ & 10. & أنثى & \\
\hline \multirow{2}{*}{$\cdot, 100$} & \multirow{2}{*}{$1, \leqslant r \leqslant$} & $r, T \leqslant V$ & Yr,VV & 10. & ذكر & \multirow{2}{*}{ والاهمية) (المغزى } \\
\hline & & $r, 0 \leqslant 1$ & TY, rO & 10. & أنثى & \\
\hline \multirow{2}{*}{ ( } & \multirow{2}{*}{$\cdot, 10 Y_{-}$} & T,M & Y1,0. & 10. & ذكر & \multirow{2}{*}{ الاستقلالي } \\
\hline & & $r, \wedge \neg \wedge$ & $\langle 1, \lambda I$ & 10. & أنثى & \\
\hline \multirow{2}{*}{ - TVO } & \multirow{2}{*}{$\cdot, \wedge \wedge q_{-}$} & $\varepsilon, \varepsilon \wedge q$ & $1 \wedge, \wedge \varepsilon$ & 10. & ذكر & \multirow{2}{*}{ التأثير } \\
\hline & & $r, 70$. & $19, Y_{7}$ & 10. & أنثى & \\
\hline \multirow{2}{*}{ - rOV } & \multirow{2}{*}{ 1, } & $\varepsilon, Y V Y$ & 11,90 & 10. & ذكر & \multirow{2}{*}{ التحفيز الذاتي } \\
\hline & & $r, v \leqslant 0$ & $19, \sum 1$ & 10. & أنثىى & \\
\hline \multirow{2}{*}{$\cdot, r 10$} & \multirow{2}{*}{$1, r \leqslant r_{-}$} & r,TVo & YI, 10 & 10. & ذكر & \multirow{2}{*}{ الإيجابية و التفاؤل } \\
\hline & & $r, 910$ & TY,Tr & 10. & أنثى & \\
\hline \multirow{2}{*}{$\cdot, V \leqslant}$. & \multirow{2}{*}{ אזr, } & r,7r4 & IV,rT & 10. & ذكر & \multirow{2}{*}{ الدافعية للتعلم } \\
\hline & & $Y, 011$ & $I V, Y T$ & 10. & أنثى & \\
\hline \multirow{2}{*}{ •,OYI } & \multirow{2}{*}{$\cdot, T \leqslant r_{-}$} & $19, \leqslant 01$ & $1 \leqslant 1, V V$ & 10. & ذكر & \multirow{2}{*}{ 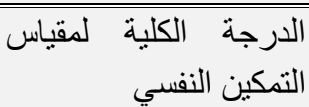 } \\
\hline & & $10,17$. & $1 \leqslant r, \cdot V$ & 10. & أنثى & \\
\hline
\end{tabular}

يتضح من الجدول السابق عدم وجود فروق بين الذكور والاناث في التمكين النفسي

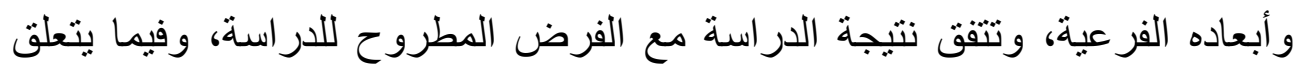

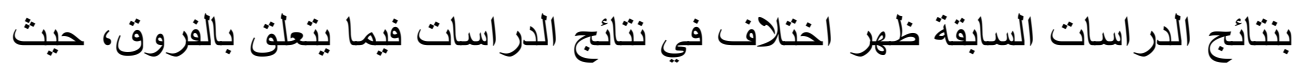

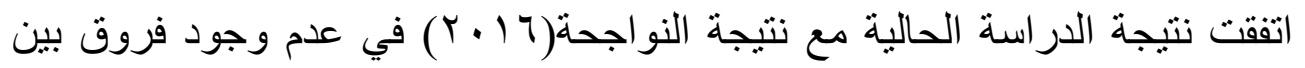

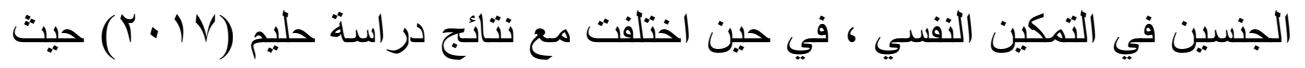

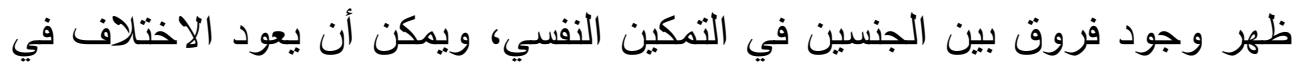

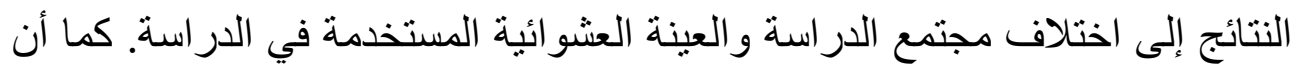
الطلاب و الطالبات من الجنسين يحصلون على نفس الفرصة في ممارسة الرقابة وتحمل المسؤولية في استخدام قدراتهم ومن خلال تشجيعهم على اتخاذ القرارات، 


\section{التربية الوقائية وعلاقتها بالتمكين النفسي}

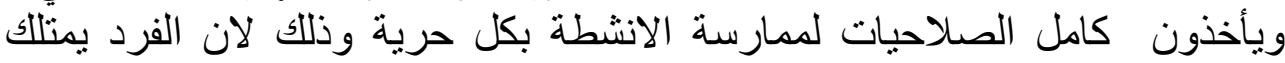

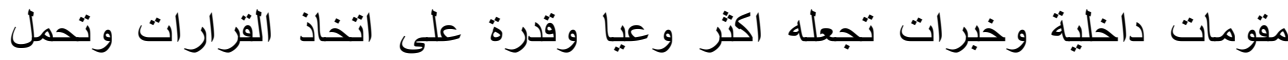

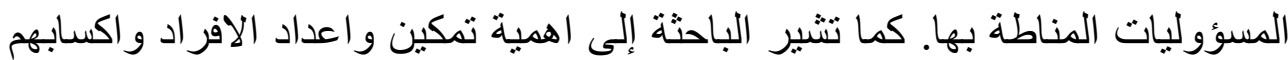

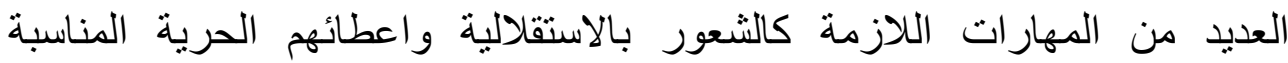

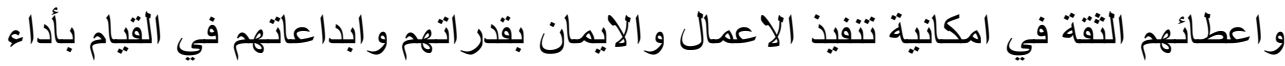

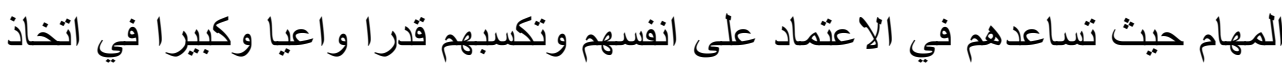

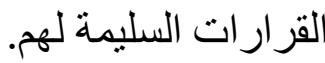
توصيات الاراسة

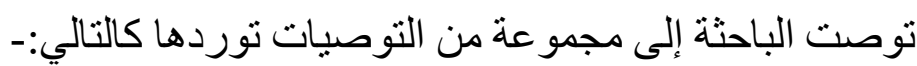
ا ـ ضرورة التعرف على طبيعة الاحتياجات الأساسية المكونة لشخصيات التيات الطلاب و الطالبات و العمل على الثباعها. r ـ العمل على زيادة الوعي الوقائي لاعى الطلاب و الطالبات بكيفية مو اجهه المشكلات

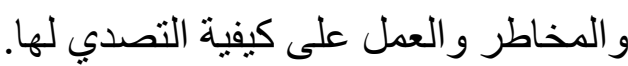

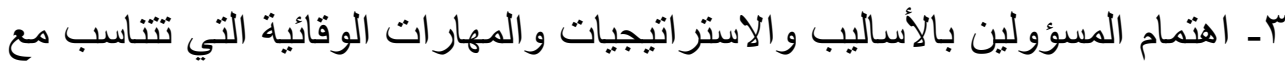

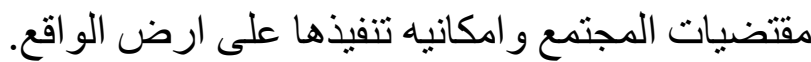
ـ ـ الوصول بالطلاب و الطالبات الى أعلى مستويات من الكفاءة و القدرة على التهات التمكين

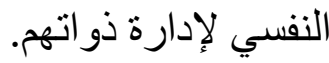
مقترحات الاراسة الارة

1 - فعالية برنامج ارشادي التتمية التربية الوقائية لدى طلاب المرحلة الثانوية

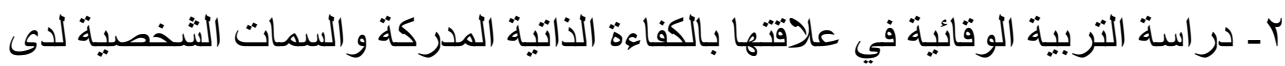

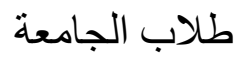

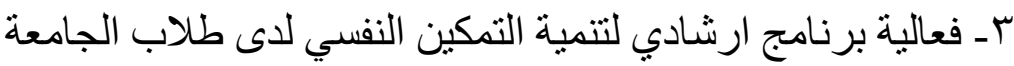

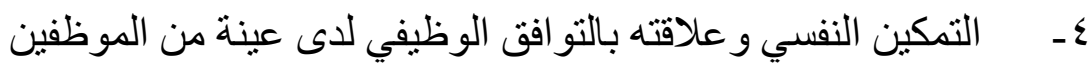




\section{أر علياء أحمد الحازمي د/ سهير محمد التوني

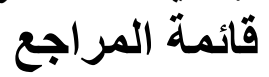

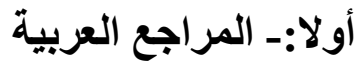

- ابو الهيجاء،شيرين ماهر محمد.بني ملحم،يحيى سليم.(2019) اثر التمكين النفسي على الادي

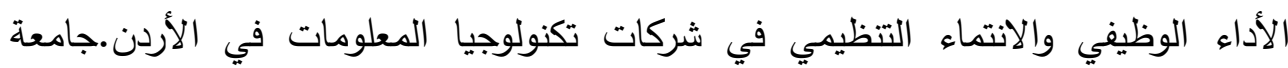
اليرموك،كلية الاقتصاد والعلوم الإدارية.127-1.

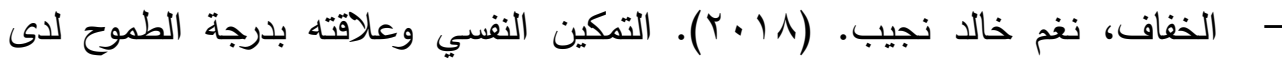

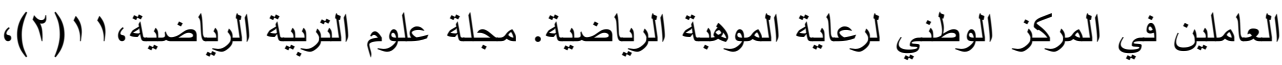
$.100-1$ rs

- ابا زيد، رياض (9 . . ץ). اثر التمكين النفسي على سلوك المواطنة للعاملين في المؤسسة

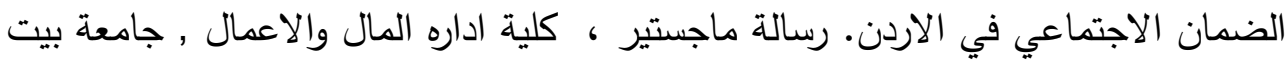

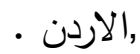

- أبو النور، محمد عبد التواب (1) • ب). التمكين النفسي للمعلمين والمعلمات بمؤسسات

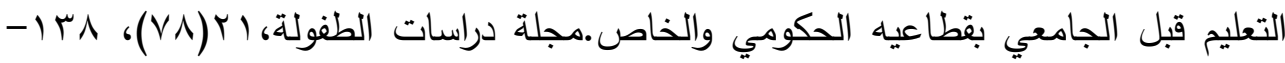
$.1 Y \mathrm{YV}$

- ابو ليفة،سناء مصطفى محمد.(2019)العلاقة بين السلوك الأخلاقي للقيادة وروحانية مكان العمل :دراسة ميدانية لدور التمكين النفسي كمتغير وسيط تداخلي في هذه العلاقة.

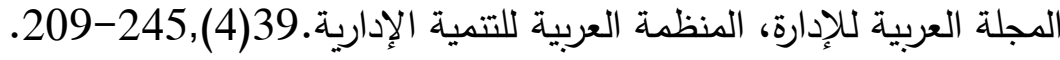

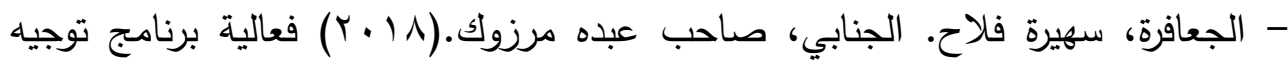
جمعي للحماية من الإساءة الجنسية في خفض التكتم الانفعالي وتتمية التمكين النفسي لاى الداع الأطفال. جامعة مؤتة،رسالة دكتوراه. IV.-1V - الثريفين، أحمد(9 (r). فعالية طرق الارشاد النفسي الابداعية في تحليل معتنتقدات

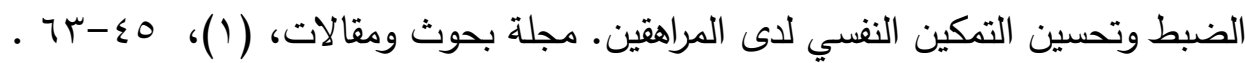




\section{التربية الوقائية وعلاقتها بالتمكين النفسي}

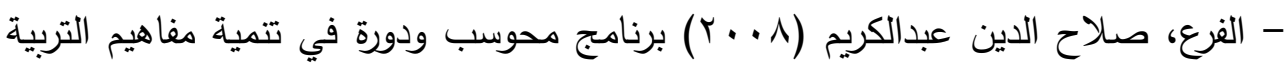
الوقائية في تكنولوجيا لاى طلبه الصف التاسع الاساسي. رساله ماجستير ، كلية التربية ،

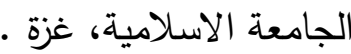

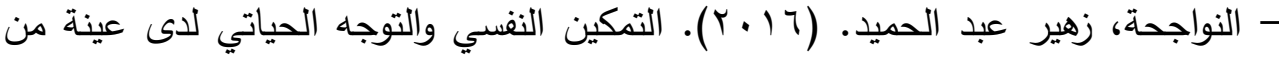
معلمي المرحلة الاساسية. مجلة جامعة القدس المفتوحة للابحاث والدراسات التربوية والنفسية .rAT-MIT، (10)؛

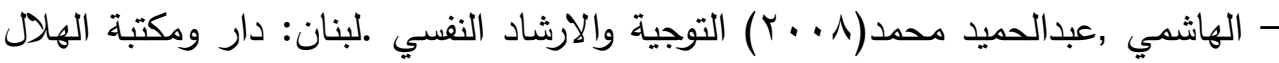

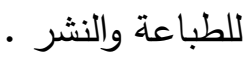

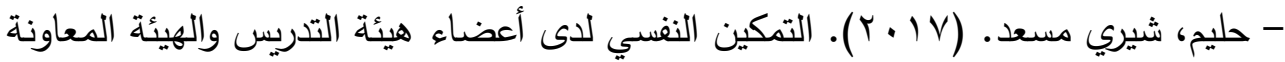

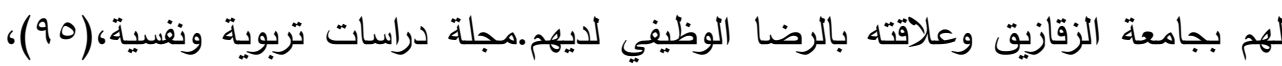
$.111-0 \mathrm{~V}$ - خليفة، مي السيد. (10 (Y). الاسهام النسبي للإدارة الإستراتيجية للموارد البشرية في

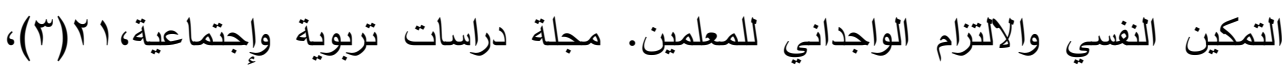
. $\wedge \wedge \varepsilon-\varepsilon 11$

- زكريا،فاطمةعصام(9 ( ب) التككين النفسي وعلاقتة ببعض المتغيرات النفسية لدى عينة من الطلاب الجامعة. رسالة ماجستير ،كلية التربية ، جامعة عين شمس.

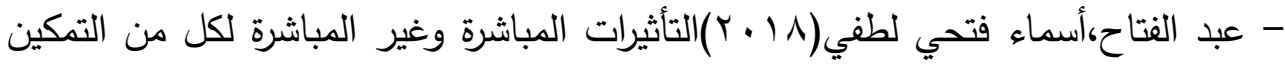
النفسي والثفقة بالذات والمثابرة الأكاديمية لدى طلاب الصفين الأول والثاني بمرحلة الثانوية

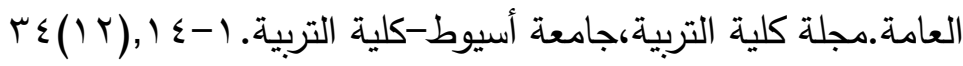

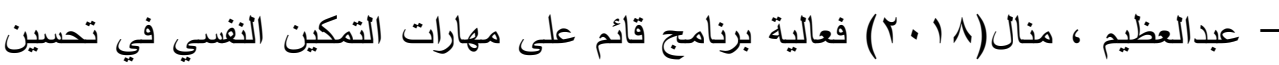
الكمالية والتوجه نحو الحياة لدى طالبات الجامعة ,مجلة , كلية التربية, جامعة الازهر

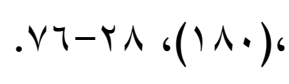

- عيدي، جاسم محمد (19 ب (Y) التمكين النفسي وعلاقتة بالصلابة النفسية لدى المرسشدين

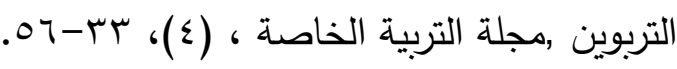




$$
\text { أ/ علياء أحمد الحازمي د// سهير محمد التوني }
$$

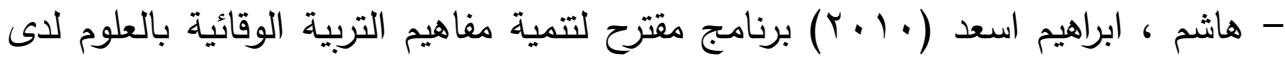
الطلاب الصف التاسع الاساسي • رسالة ماجستير ،كلية التربية ،الجامعة الاسلامية، غزة ـ

$$
\text { ثانيا:- المراجع الاجنبية }
$$

- Christens, B. D., Peterson, C. H., \& Speer, P. W. (2014).

Psychological empowerment in adulthood. In Encyclopedia of primary prevention and health promotion (pp. 1766-1776). Springer US.

- Martin,N.\& Rice,J.(2010). Cybercrime:Understanding and addressing the concerns of Stakeholders.Computers\&

Securty,30(8),803-814.

- Safari, K., Haghighi, A. S., Rastegar, A., \& Jamshidi, A. (2011).

The relationship between psychological empowerment and organizational learning. Procedia-Social and Behavioral Sciences, 30, 1147-1152

- Tastam, S. B. (2013). The relationship between psychological empowerment and psychological well being: the role of self-efficacy perception and social support. Öneri Dergisi, 10(40), 139-154.

- Telef. (2011). the study of teachers self-efficacy, job satisfaction and burnout .elementary education on line, 10(1), 91-108.

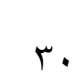




\section{التربية الوقائية وعلاقتها بالتمكين النفسي}

Preventive Education and its relationship with Empowerment Psychological among a sample of high school students in Makkah. Abstract:-

This study aimed to identify the relation between Preventive Education and Empowerment Psychological among a sample of high school students in Makkah. also identify how different between male and female in Preventive Education and Empowerment Psychological This study includes a sample of high school students in Makkah $(\mathrm{N}=300) \quad$ (150 male and 150female). In this study the researchers used Preventive Education scale and Empowerment Psychological scale ,the result refiled that there is a relation between Preventive Education and Empowerment Psychological among a sample of high school students in Makkah, there is no different between male and female in Preventive Education and Empowerment Psychological.

Key words:- Preventive Education - Empowerment Psychological high school students 